\title{
Review
}

\section{Mixed states in bipolar and major depressive disorders: systematic review and quality appraisal of guidelines}

\author{
Verdolini N, Hidalgo-Mazzei D, Murru A, Pacchiarotti I, Samalin L, \\ Young AH, Vieta E, Carvalho AF. Mixed states in bipolar and major \\ depressive disorders: systematic review and quality appraisal of \\ guidelines.
}

Objective: This systematic review provided a critical synthesis and a comprehensive overview of guidelines on the treatment of mixed states. Method: The MEDLINE/PubMed and EMBASE databases were systematically searched from inception to March 21st, 2018.

International guidelines covering the treatment of mixed episodes, manic/hypomanic, or depressive episodes with mixed features were considered for inclusion. A methodological quality assessment was conducted with the Appraisal of Guidelines for Research and Evaluation-AGREE II.

Results: The final selection yielded six articles. Despite their heterogeneity, all guidelines agreed in interrupting an antidepressant monotherapy or adding mood-stabilizing medications. Olanzapine seemed to have the best evidence for acute mixed hypo/manic/ depressive states and maintenance treatment. Aripiprazole and paliperidone were possible alternatives for acute hypo/manic mixed states. Lurasidone and ziprasidone were useful in acute mixed depression. Valproate was recommended for the prevention of new mixed episodes while lithium and quetiapine in preventing affective episodes of all polarities. Clozapine and electroconvulsive therapy were effective in refractory mixed episodes. The AGREE II overall assessment rate ranged between $42 \%$ and $92 \%$, indicating different quality level of included guidelines.

Conclusion: The unmet needs for the mixed symptoms treatment were associated with diagnostic issues and limitations of previous research, particularly for maintenance treatment.

\author{
N. Verdolini ${ }^{1,2,3,4}$, D. Hidalgo- \\ Mazzei $^{1,3,5}$, A. Murru ${ }^{1,3}$, \\ I. Pacchiarotti ${ }^{1,3}$, L. Samalin ${ }^{1,6,7}$, \\ A. H. Young ${ }^{5}$, E. Vieta ${ }^{1,3}$ (D), \\ A. F. Carvalho ${ }^{8,9}$
}

${ }^{1}$ Bipolar Disorder Unit, Institute of Neuroscience, Hospital Clinic, IDIBAPS, CIBERSAM, University of Barcelona, ${ }^{2}$ FIDMAG Germanes Hospitalàries Research Foundation, Sant Boi de Llobregat, ${ }^{3}$ CIBERSAM, Centro Investigación Biomédica en Red Salud Mental,

Barcelona, Spain, ${ }^{4}$ Division of Psychiatry, Clinical Psychology and Rehabilitation, Department of Medicine, Santa Maria della Misericordia Hospital, University of Perugia, Perugia, Italy, ${ }^{5}$ Department of Psychological Medicine, Centre for Affective Disorders, Institute of Psychiatry, Psychology \& Neuroscience, King's College London, London, UK, ${ }^{6}$ Department of Psychiatry, $\mathrm{CHU}$ Clermont-Ferrand, University of Auvergne, ClermontFerrand, ${ }^{7}$ Fondation FondaMental, Pôle de Psychiatrie, Hôpital Albert Chenevier, Créteil, France, ${ }^{8}$ Department of Psychiatry, University of Toronto, and ${ }^{9}$ Centre of Addiction and Mental Health (CAMH), Toronto, ON, Canada

Key words: mixed states; mixed features; bipolar disorder; unipolar disorder; guidelines

Eduard Vieta, Bipolar Disorder Unit, Institute of Neuroscience, Hospital Clinic, IDIBAPS, CIBERSAM, University of Barcelona, 170 Villarroel st, 12-0, 08036 Barcelona, Spain

E-mails: EVIETA@clinic.cat; NVERDOLINI@clinic.cat

Accepted for publication April 17, 2018

\section{Summations}

- Olanzapine seemed to be the most effective compound for the treatment of acute mixed hypo/manic or depressive states as well as for the prevention of affective episodes of any polarity, even though the available evidence was still scant.

- Aripiprazole and paliperidone in monotherapy could be effective alternatives in the treatment of acute hypo/manic mixed states while lurasidone and ziprasidone (in combination with treatment as usual) in the treatment of acute depressive manifestations. As for the maintenance treatment, valproate was effective in the prevention of new mixed episodes. Lithium and the combination treatment of quetiapine were useful in preventing affective episodes of all polarities.

- Antidepressant monotherapy should be avoided while clozapine and electroconvulsive therapy were effective options in treatment resistant patients. 


\section{Verdolini et al.}

\section{Considerations}

- Different diagnostic criteria have been used to define manic/hypomanic and depressive presentations (mixed episodes or mixed features).

- All the guidelines included lack of strength in the AGREE II applicability domain. The quality of the British Association for Psychopharmacology guidelines was the best, but the World Federation of Societies of Biological Psychiatry guidelines represented the most focused guidelines on the treatment of mixed states. The Stahl and colleagues' guidelines were the first ones to address depression with DSM-5 mixed features, but the rigor of development was inconsistent.

- The available evidence on the treatment of mixed patients had been generally extrapolated from post hoc or pooled analyses of randomized clinical trials. The findings of this critical systematic review should be kept with caution as the generalizability of these results might be partly suitable for the treatment of mania with mixed features but are less likely applicable to the treatment of depression with mixed features.

\section{Introduction}

Bipolar disorder (BD) is a severe chronic mood disorder broadly classified according to the longitudinal course in BD type I (BDI) or type II (BDII) and characterized by episodes of mania, hypomania, and alternating or intertwining episodes of depression with the presence of subthreshold symptoms between the episodes (1). A complex and quite frequent presentation of BD is represented by the occurrence of mixed states, historically defined as the coexistence of depressive and manic symptoms (2).

The identification of mixed features in $\mathrm{BD}$ and major depressive disorder (MDD) is an open challenge in psychiatry as an accurate diagnosis is a pre-requisite for the initiation of adequate therapeutic approaches (3-5). The mixed episode was defined by juxtaposed full manic and depressive episodes in the diagnostic and statistical manual of mental disorders-IV-text revision (DSM-IV-TR) (6). A 'with mixed features' specifier (MFS) has been incorporated in the DSM-5 (7); this specifier may be applied to manic episodes in BDI, hypomanic episodes in BDI and BDII, and to major depressive episodes (MDE) experienced in BDI, BDII, BD not otherwise specified (BD-NOS) as well as in MDD (8). As a consequence, hypomanic symptoms could currently denote both MDD or $\mathrm{BD}$ and many individuals along the mood disorders spectrum that were previously 'orphans' of a diagnosis could be classified according to a 'mixedcategorical-dimensional' approach $(8,9)$.

Approximately $30-40 \%$ of major affective episodes that occur over the course of $\mathrm{BD}$ appear to exhibit mixed features (10-12). Major concerns still exist for the DSM-5 MFS. In fact, it has $100 \%$ specificity but only $5.1 \%$ sensitivity (5).
Specificity at the expense of sensitivity suggests that up to $95 \%$ of patients presenting with the MFS according to the DSM-5 are wrongly diagnosed as having 'pure' affective episodes (i.e., without mixed features) $(5,9)$. The DSM-5 workgroup excluded overlapping symptoms such as distractibility, irritability, and psychomotor agitation, arguing that they may lack the ability to differentiate between manic and depressive states (13), in the choice of a more 'specific' approach at the expenses of the 'sensitivity' of the classification $(8,9)$. Nevertheless, when criteria that consider overlapping symptoms for the diagnosis of mixed features are used, a more balanced trade-off between sensitivity and specificity was obtained, with a specificity of $87 \%$ and a sensitivity as high as $55 \%(5,14)$. In addition, it is not clear which could be the implication on the prevalence of mixed episodes of the DSM-5 MFS in comparison with previous DSM classifications, as literature findings are conflicting. In BD, DMS-5 mixed features rates were found to be threefold higher than DSM-IV-TR mixed episodes in a retrospective naturalistic study (15) while the Bipolar CHOICE, a randomized comparative effectiveness trial, reported that fewer patients suffering from BD met mixed criteria with the DSM-5 nonoverlapping definition compared to the DSM-IV (16). In the multicenter, multinational cross-sectional bipolar disorders: Improving Diagnosis, Guidance and Education (BRIDGE)-II-MIX study, 7.5\% of the entire sample fulfilled DSM-5 criteria for MDE with mixed features, but when a broader definition including overlapping symptoms was applied, the rates of depressive mixed states were as high as $29.1 \%$ (17).

The DSM-5 does not provide a clear rationale for not weighing certain depressive symptoms, 
such as weight loss or weight gain, decreased or increased appetite, and insomnia or hypersomnia for the establishment of a MFS in the context of mania (or hypomania) even though virtually every symptom of depression may co-occur in acute (hypo)manic episodes (18). Many patients with MDE and mixed features also present with manifestations of anxiety that are not captured by the MFS (18) as well as other clinical features, that is, aggressiveness that have been recently found to be a possible psychopathological indication of an underlying mixed state (19). A recent study identified that a four- or five-symptom cluster composed by the DSM-5 MFS symptoms racing thoughts, increased talkativeness and decreased need for sleep and by the two non-specific symptoms distractibility and irritability, was shown at baseline in a placebo-controlled trial involving patients with MDD with mixed features (20). Hence, it has been hypothesized that the symptoms of the DSM5 MFS are themselves non-specific (21).

The introduction of a codable diagnostic entity defined according to the MFS should provide a rationale for the selection of distinct therapeutic strategies (9). Nonetheless, no drug treatment has been approved by major regulatory agencies for the management of affective episodes with a MFS (22). The treatment of mixed episodes is an important challenge for psychiatrists as the available evidence is undermined by the methodological limitations of previous RCTs. Generally, the response to pharmacological agents of patients presenting a manic episode with depressive mixed symptoms had been extrapolated from post hoc or pooled analyses of RCTs evaluating treatment response in mania (23). In addition, these studies generally did not provide data for the mixed subgroup (22). The evidence for mixed depression is even more scant as patients presenting mixed symptoms are generally excluded by depression RCTs (24). As a consequence, the generalizability of the results of previous RCT may be partly suitable for the treatment of mania with mixed features but are less likely applicable to the treatment of depression with mixed features (25).

The treatment of mixed states represented an unmet need in previous international guidelines of BD. Indeed, clinicians should follow existing guidelines written for the treatment of MDD or $\mathrm{BD}$ with few indications for patients presenting with mixed symptoms in spite of the high frequency and clinical significance of mixed states over the course of mood disorders (26).

Only recently, the World Federation of Societies of Biological Psychiatry (WFSBP) published guidelines for the acute and long-term treatment of mixed episodes in BDI (22) and treatment guidelines addressing the DSM-5 MFS during a MDE have also been developed (5). The Florida Best Practice Psychotherapeutic Medication Guidelines for Adults With Major Depressive Disorder (27) and the Korean Medication Algorithm Project for Bipolar Disorder: Third Revision (28) specifically addressed the treatment of mixed features. In addition, the available updated editions of the international guidelines for BD reported recommendations for the treatment of mixed episodes and mixed symptoms.

\section{Aims of the study}

As mixed features represent a challenge for clinicians at the diagnostic, classification, and pharmacological treatment levels, the aim of this work was to summarize available evidence and to provide a comprehensive review of recently updated guidelines. This work was part of a systematic review protocol of current treatment guidelines for mood disorders, and this particular study focused exclusively on the treatment of mixed states and symptoms. A critical approach has been applied to identify areas of consensus and controversy, to underline the strengths and limitations of available evidence, and also the methodological quality of international guidelines that provided evidence for the management of mixed states in the context of bipolar disorder and major depressive disorder. Finally, unmet needs were identified to provide direction for further research.

\section{Methods}

This systematic review followed the Preferred Reporting Items for Systematic Reviews and MetaAnalyses (PRISMA) statement (29). A study protocol was registered with PROSPERO and published a priori (CRD42018078199).

\section{Search strategy}

The MEDLINE/PubMed and EMBASE databases were searched up to March 21st, 2018. Detailed search strings are provided in the Supporting Information that accompanies the online version of this article.

This search strategy was augmented through hand-searching of the reference lists of included articles. Duplicate publications were identified and cross-referenced to optimize information. Two independent reviewers (NV and DHM) screened the title/abstracts of retrieved references for 


\section{Verdolini et al.}

eligibility, evaluated the full-texts of potentially eligible articles, performed the methodological assessment of guidelines, and extracted pre-established relevant information. Disagreements were resolved through consensus, and a third investigator was consulted whenever a consensus could not be achieved (AM).

\section{Eligibility criteria}

International guidelines for the treatment of mixed episodes, manic/hypomanic (in BDI, BDII, and BD-NOS), or depressive episodes (in BDI, BDII, BD-NOS, and MDD) with mixed features published in any language were considered for inclusion.

The Institute of Medicine definition of guidelines as 'statements that include recommendations intended to optimize patient care that are informed by a systematic review of evidence and an assessment of the benefits and harms of alternative care options' (30) was considered as an operational criteria to define included guidelines.

International guidelines were defined as guidelines performed by: (i) an international organization, representing more than a single country; (ii) a panel of experts from different countries; (iii) a national organization providing that experts from at least three different countries participated in the development of the guideline.

Only guidelines for BD updated from 2011 onwards have been considered in this critical review since guidelines published before those dates have been critically examined elsewhere (3133). As for guidelines for MDD, only those guidelines updated from 2013 (when the MFS has been introduced) have been considered.

Guidelines were included if they clearly outlined their development and the clinical recommendations' procedures. When available, tables and/or algorithms of medication phases were consulted.

\section{Data extraction}

The following information was extracted for each article when available: international organization; publication year; date of the last search; evidence category of treatment options; grading of safety and tolerability.

Treatment recommendations were reported for (i) mixed episodes according to DSM-IV-TR and (ii) mixed features according to DSM-5. When available, data concerning both acute and longterm treatment were described and treatment options were specified for the depressive or manic polarities of mixed episodes or features.
As for efficacy evidence, treatment options were categorized into first-line, second-line, and not recommended treatments in accordance with an adaptation of procedures described elsewhere (31). The category of evidence (CE) describing the level of efficacy was specified for each treatment option in Table S1 of the Supporting Information that accompanies the online version of this article. Specifications on safety and tolerability issues were also extrapolated when available. In general, but not in all the included guidelines, safety and tolerability aspects were integrated with the $\mathrm{CE}$ assigned to each compound leading to different recommendation grades (RG). In the purpose of this critical review, we created an operational definition of first- and second-line treatment recommendations, grouping the $\mathrm{RG}$ of the different guidelines (see Table S2).

\section{Methodological quality assessment}

The methodological quality assessment of included guidelines was carried out with the Appraisal of Guidelines for Research and Evaluation (AGREE) II tool (34). The AGREE II was designed to provide a framework to assess the quality of guidelines judging the methods used for developing the guidelines, the components of the final recommendations, and the factors that were linked to their uptake on the basis of six domains (i.e., scope and purpose, stakeholder involvement, rigor of development, clarity of presentation, applicability, and editorial independence).

An electronic group appraisal was created at the My AGREE Plus website (35), and after successfully completing training modules, the two reviewers (NV and DHM) undertook independent appraisals for each of the included guidelines. The scores rated by the two reviewers for the 23 items of the AGREE II, for the six domains, and for the overall quality of the guideline were calculated and scaled according to the AGREE II scoring instructions.

\section{Results}

Systematic search results

The initial search returned 7622 hits (Figure S1). Following removal of duplicates, the title/abstracts of 5280 references were screened for eligibility, and 5261 references were excluded. The full texts of 19 references concerning structured treatment algorithms and/or guidelines suggested by official panels were scrutinized in detail for eligibility. Among them, 13 references were 


\section{Mixed states and features treatment review}

Table 1. Comparison of the included guidelines: evidence of efficacy, acute treatment, first line

\begin{tabular}{|c|c|c|c|}
\hline First line & Guidelines & $\begin{array}{l}\text { Mania/hypomania with mixed features } \\
\text { or manic mixed episode }\end{array}$ & $\begin{array}{l}\text { Depression with mixed features or depressive } \\
\text { mixed episode }\end{array}$ \\
\hline \multirow[t]{6}{*}{ Monotherapy } & BAP 3rd edition & Oral SGA (I) & - \\
\hline & CANMAT/ISBD 2018 & SGA: ASN, ARP, OLZ and ZPD (1) & SGA: LUR (2) \\
\hline & CINP-BD-2017 & - & - \\
\hline & RANZCP Mood Disorders CPG & - & $\begin{array}{l}\text { SGA: OLZ, OTP } \\
\text { MS: VPA }\end{array}$ \\
\hline & Mixed depression guidelines & - & $\begin{array}{l}\text { SGA: LUR, ASN, OTP, OTP-XR, ARP and ZPD (1); } \\
\text { OLZ and CAR (2) } \\
\text { MS: LMT, VPA and Li (2) }\end{array}$ \\
\hline & WFSBP Mixed states & $\begin{array}{l}\text { SGA: OLZ (A, for ManS), ARP (B, for ManS } \\
\text { and DepS) and PLP (B, for ManS) }\end{array}$ & - \\
\hline \multirow[t]{6}{*}{ Combination } & BAP 3rd edition & $\begin{array}{l}\mathrm{CLZ}+\mathrm{Li} \text { or MS in treatment resistant patients } \\
+\mathrm{BDZ}\end{array}$ & - \\
\hline & CANMAT/ISBD 2018 & SGA + VPA: ASN (2), ARP (2), OLZ (1) & $\begin{array}{l}\mathrm{LUR}+\mathrm{Li} / \mathrm{VPA}(1) \\
\text { OFC (2) }\end{array}$ \\
\hline & CINP-BD-2017 & $\mathrm{OLZ}+\mathrm{MS}(2)$ & $\mathrm{OLZ}+\mathrm{MS}(2)$ \\
\hline & RANZCP Mood Disorders CPG & SGA (ASN, OLZ, ARP, ZPD, RPD) + MS (II) & $\begin{array}{l}\text { SGA (OLZ, OTP) or VPA + AD (II) } \\
\text { VPA + OLZ (II) }\end{array}$ \\
\hline & Mixed depression guidelines & - & $\begin{array}{l}\text { MS (Li, LMT, VPA })+S G A \\
L i+V P A \\
L i+V P A+L M T \\
\text { OFC }\end{array}$ \\
\hline & WFSBP Mixed states & $\begin{array}{l}\text { OLZ + VPA (A for ManS and DepS) } \\
\text { OTP + MS (B for DepS) }\end{array}$ & ZPD + TAU \\
\hline
\end{tabular}

AD, antidepressants; ARP, aripiprazole; ASN, asenapine; BAP, British Association of Psychopharmacology; BD, bipolar disorder; BDZ, benzodiazepines; CANMAT, Canadian Network for Mood and Anxiety Treatment; CAR, cariprazine; CINP, International College of Neuropsychopharmacology; CLZ, clozapine; CPG, clinical practice guidelines; DepS, depressive symptoms; ISBD, International Society of Bipolar Disorder; ManS, manic symptoms; Li, lithium; LMT, lamotrigine; LUR, lurasidone; OFC, olanzapine+fluoxetine; OLZ, olanzapine; PLP, paliperidone; OTP, quetiapine; RANZCP, Royal Australian and New Zealand College of Psychiatrists; RPD, risperidone; SGA, second generation antipsychotics; TAU, treatment as usual; VPA, valproate; WFSBP, World Federation of Societies of Biological Psychiatry; ZPD, ziprasidone; XR, extended-release.

(I), (1), (A), first category of evidence; (II), (2), (B), second category of evidence.

excluded with reasons (see Table S3). The final selection yielded six articles.

\section{Content results}

Evidence of efficacy was summarized in Table 1 (acute treatment, first-line), Table 2 (acute treatment, second-line), Table 3 (maintenance treatment), and Table S4 (not recommended treatment).

\section{Evidence of efficacy}

Evidence-based guidelines for treating bipolar disorder: revised third edition recommendations from the British Association for Psychopharmacology. The BAP updated previous guidelines (26) and provided this third revision based on the best new available evidence from RCTs and observational studies employing quasi-experimental designs (36). The Grading of Recommendations Assessment, Development and Evaluation (GRADE) approach (37) was used to grade the recommendations and was preferred to the traditional evidence categories (38) as this approach downgraded non-experimental descriptive studies in favor of any RCT, even of small clinical trials where bias was highly likely. The strength of the evidence was instead rated on the basis of traditional evidence categories (38) and may relate to both RCT and observational findings. Along with the grading of a strategy or individual treatment, the BAP provided recommendations that were not based on systematic evidence but represented an important practical or ethical consensus between the authors that could influence practice (Standard of Care, S).

Canadian Network for Mood and Anxiety Treatments (CANMAT)/International Society for Bipolar Disorders (ISBD) 2018 guidelines for the management of patients with bipolar disorder. The CANMAT in collaboration with the ISBD updated the guidelines, and the evidence ratings have been modified from the previous editions to increase rigor (39). A final grading of recommendations into first-, second-, or third-line was listed, and a new hierarchical order of treatments was created for first- and second-line recommendations, considering levels of evidence for efficacy of each treatment, as well as acute and maintenance safety and tolerability and risk of treatment emergent switch. In the sections dedicated to the acute and long-term management of bipolar mania/hypomania and depression, the authors reported about the new mixed feature specifier in the specific section about 'clinical features that help 


\section{Verdolini et al.}

Table 2. Comparison of the included guidelines: evidence of efficacy, acute treatment, second line

\begin{tabular}{|c|c|c|c|}
\hline Second line & Guidelines & $\begin{array}{l}\text { Mania/hypomania with mixed features } \\
\text { or manic mixed episode }\end{array}$ & $\begin{array}{l}\text { Depression with mixed features or } \\
\text { depressive mixed episode }\end{array}$ \\
\hline \multirow[t]{10}{*}{ Monotherapy } & BAP 3rd edition & LMT (IV) & - \\
\hline & CANMAT/ISBD 2018 & ZPD (3) for mixed hypomania & - \\
\hline & CINP-BD-2017 & SGA: ARP, ASN, PLP, RPD, OLZ (3), and ZPD (4) & SGA: ARP, ASN, OLZ (3), and ZPD (4) \\
\hline & & MS: VPA, CBZ (3) & MS: VPA (4) , CBZ (3) \\
\hline & & OFC (4) & $\mathrm{OFC}(4)$ \\
\hline & Mixed depression guidelines & - & MS: CBZ (3) \\
\hline & WFSBP Mixed states & SGA: ASN (C for DepS), RPD (C), CAR (C for ManS), CLZ & SGA: LUR, OLZ (C) \\
\hline & & $\begin{array}{l}\text { (C for ManS), OLZ (C for DepS), ZPD (C for ManS and } \\
\text { DepS) }\end{array}$ & MS: CBZ (C for DepS) \\
\hline & & FGA & \\
\hline & & MS: VPA (C for ManS), CBZ (C for ManS and DepS) & \\
\hline \multirow[t]{11}{*}{ Combination } & BAP 3rd edition & ECT (IV) & - \\
\hline & CINP-BD-2017 & - & - \\
\hline & RANZCP Mood Disorders CPG & ECT (III) & - \\
\hline & Mixed depression guidelines & - & $\mathrm{CBZ}+\mathrm{Li}(3)$ \\
\hline & & & Li + pramipexole (3) \\
\hline & & & $\mathrm{Li}+\mathrm{ECT}(3)$ \\
\hline & & & MS: (Li, LMT, VAP) or SGA + bupropion or SSRI or MAOI (3) \\
\hline & WFSBP Mixed states & SGA: OTP (C for ManS), CLZ (C for ManS), & ECT $(C)$ \\
\hline & & MS: OXC (+ Li, C for ManS), GBP (C, for ManS and DepS), & \\
\hline & & TPR (D for ManS) & \\
\hline & & ECT (C for ManS and DepS) & \\
\hline
\end{tabular}

AD, antidepressants; ARP, aripiprazole; ASN, asenapine; BAP, British Association of Psychopharmacology; BD, bipolar disorder; CANMAT, Canadian Network for Mood and Anxiety Treatment; CBZ, carbamazepine; CAR, cariprazine; CINP, International College of Neuropsychopharmacology; CLZ, clozapine; CPG, clinical practice guidelines; DepS, depressive symptoms; ECT, elettroconvulsive therapy; FGA, first-generation antipschotics; GBP, gabapentin; ISBD, International Society of Bipolar Disorder; ManS, manic symptoms; OXC, oxcarbazepine; Li, lithium; LMT, lamotrigine; LUR, lurasidone; MAOI, monoamine oxidase inhibitor; OFC, olanzapine+fluoxetine; OLZ, olanzapine; PLP, paliperidone; OTP, quetiapine; RANZCP, Royal Australian and New Zealand College of Psychiatrists; RPD, risperidone; SGA, second-generation antipsychotics; SSRI, selective serotonin reuptake inhibitor; TAU, treatment as usual; TPR, topiramate; VPA, valproate; WFSBP, World Federation of Societies of Biological Psychiatry; ZPD, ziprasidone; XR, extended-release. (III), (3), (C), third category of evidence; (IV), (4), (D), fourth category of evidence.

direct treatment choices'. Unfortunately, the task force did not grade the efficacy of treatments for acute and long-term management of mixed features during bipolar mania and depression but only for hypomania. The authors of this systematic review decided to extrapolate the $\mathrm{CE}$ for mixed features from the corresponding bipolar mania and depression recommendations.

The International College of Neuro-Psychopharmacology treatment guidelines for Bipolar disorder in adults (CINP-BD-2017). The CINP recently proposed the first edition of the treatment guidelines for patients with BDI or BDII in primary and secondary care and addressed the treatment of adult patients with mixed features, rapid cycling, and psychotic features but not children, adolescents, or the elderly (40). The authors reviewed data from clinical trials and meta-analyses, reserved the privilege to judge, and use data from open trials, reviews, and opinion letters on an individual basis, according to their research and clinical experience, took into consideration guidelines developed during the last 10 years, and recommendations were stated by consensus through the Delphi method. The workgroup decided to develop a grading method for the evaluation of available data, which is an adaptation of the GRADE. After the grading of data and interventions, the authors created a precise algorithm for experimental reasons and finally establish recommendations.

As for mixed states, the workgroup stated that data suggested that mixed features respond to treatment in a different way than DSM-IV-TR mixed episodes. The workgroup separately provided effects on the manic and the depressive component of mixed episodes of the most important compounds.

Royal Australian and New Zealand College of Psychiatrists clinical practice guidelines for mood disorders (Mood Disorders CPG). The RANZCP developed the Mood Disorders Clinical Practice Guideline (Mood Disorders CPG) as part of the RANZCP CPG Project 2013-2015 (41). The Mood Disorder CPG is the first Clinical Practice Guideline to address both MDD and BD, coherently with the conceptualization of a mood spectrum. The levels 


\section{Mixed states and features treatment review}

Table 3. Comparison of the included guidelines: evidence of efficacy, maintenance treatment

\begin{tabular}{|c|c|c|}
\hline $\begin{array}{l}\text { Maintenance } \\
\text { treatment }\end{array}$ & Guidelines & Mania/hypomania or depression with mixed features or manicor depressive mixed episode \\
\hline Monotherapy & $\begin{array}{l}\text { BAP 3rd edition } \\
\text { CANMAT/ISBD } 2018 \\
\text { CINP-BD-2017 } \\
\text { RANZCP Mood Disorders CPG } \\
\text { Mixed depression guidelines } \\
\text { WFSBP Mixed states }\end{array}$ & $\begin{array}{l}\text { MS: Li (I) } \\
\text { OTP in preventing episodes of any mood episode, of depression and mania, first line } \\
\text { SGA: OLZ (1) } \\
\text { VPA }>>\text { Li; CBZ? } \\
\text { The same effective acute treatment } \\
\text { 1. After an acute mixed episode in preventing episodes of any polarity, first line. Li (B for manic and for any type } \\
\text { of episode), OLZ (B), OTP (B, for manic, depressive and any type of episode) } \\
\text { 2. After an acute mixed episode in preventing episodes of any polarity, second line. ZPD (C, for manic relapse) } \\
\text { 3. After an acute manic or depressed episode in preventing new mixed episodes, first line. VPA (B) } \\
\text { 4. After an acute manic or depressed episode in preventing new mixed episodes, second line. Li (D) or OLZ (D) }\end{array}$ \\
\hline Combination & $\begin{array}{l}\text { BAP 3rd edition } \\
\text { CANMAT/ISBD } 2018 \\
\text { CINP-BD-2017 } \\
\text { RANZCP Mood Disorders CPG } \\
\text { Mixed depression guidelines } \\
\text { WFSBP Mixed states }\end{array}$ & $\begin{array}{l}- \\
\text { OTP + Li/NAP in preventing episodes of any mood episode, of depression and mania, first line. } \\
\text { ARP + MS (2) } \\
- \\
\text { AD } \\
\text { 1. After an acute mixed episode in preventing episodes of any polarity, first line. OTP + Li or VPA (A for manic, } \\
\text { depressive episode and any type of episode) or ECT (C) } \\
\text { 2. After an acute mixed episode in preventing episodes of any polarity, second line. RPD (C), ARP + LMT (C, for } \\
\text { depressive episodes) } \\
\text { 3. After an acute manic or depressed episode in preventing new mixed episodes, first line } \\
\text { 4. After an acute manic or depressed episode in preventing new mixed episodes, second line }\end{array}$ \\
\hline
\end{tabular}

AD, antidepressants; ARP, aripiprazole; ASN, asenapine; BAP, British Association of Psychopharmacology; BD, bipolar disorder; CANMAT, Canadian Network for Mood and Anxiety Treatment; CBZ, carbamazepine; CINP, International College of Neuropsychopharmacology; CLZ, clozapine; CPG, clinical practice guidelines; ECT, elettroconvulsive therapy; ISBD, International Society of Bipolar Disorder; Li, lithium; LMT, lamotrigine; OLZ, olanzapine; OTP, quetiapine; RANZCP, Royal Australian and New Zealand College of Psychiatrists; RPD, risperidone; SGA, second generation antipsychotics; VPA, valproate; WFSBP, World Federation of Societies of Biological Psychiatry; ZPD, ziprasidone. (I), (1), (A), first category of evidence; (II), (2), (B), second category of evidence; (III), (3), (C), third category of evidence; (IV), (4), (D), fourth category of evidence.

of evidence were assigned and adapted from the Australian National Health and Medical Research Council (NHMRC) levels of evidence for intervention studies (42). The Mood Disorders CPG gave two types of recommendations: (i) Evidence-based recommendations (EBRs) formulated when evidence from intervention studies was sufficient and consistent to support a recommendation on a given topic. For each EBR, strength of evidence was rated using the NHMRC levels of evidence. (ii) Consensus-based recommendation (CBR), derived through discussion and agreement within the workgroup on specific aspects of mood disorders whose nature and management are incomplete.

As little is known about the diagnosis and treatment of mixed features presentations as defined by DSM-5 (Malhi, 2013, 2014), the authors concluded that treatment guidelines for mixed features rely heavily on clinical experience and consensus recommendations.

Guidelines for the recognition and management of mixed depression. As stated by the workgroup, one of the most important challenges derived by the new DSM-5 MFS is to optimize the treatment for patients with depression exhibiting concomitant subthreshold hypo/manic features (43). With this aim in mind, a panel of experts on mood disorders has been assembled to develop guidelines on the recognition and treatment of mixed depression made in reference to DSM-5.

The World Federation of Societies of biological psychiatry guidelines for the biological treatment of bipolar disorders: acute and long-term treatment of mixed states in bipolar disorder. The international taskforce of the WFSBP developed this practice guideline specifically for acute and maintenance pharmacological treatment and prevention of mixed episodes in BD (22). Considering the topic of this critical review, we decided to include this brand-new guideline about mixed episodes and to exclude previous guidelines from the same taskforce about acute mania (23), bipolar depression (44), and maintenance treatment of BD (45).

The authors distinguished the recommendations for the following categories: (i) treatment of acute manic mixed episodes; (ii) treatment of acute depressive mixed episodes; (iii) maintenance treatment after an acute mixed episode in preventing episodes of any polarity; (iv) maintenance treatment after an acute manic or depressed episode in preventing new mixed episodes.

The ranking of evidence was the same used in the development of other guidelines of the WFSBP (46). Categories of evidence (CE) A or B, corresponding to RG 1-3, were defined for treatments that have shown their efficacy in double-blind 


\section{Verdolini et al.}

placebo-controlled studies. Lower level of evidence was recorded for open studies (CE 'C') or conflicting results (CE 'D') (low RG 4 or 5 respectively). Deviations from the original WFSBP guideline grading system were the role of post hoc and subgroup analyses as well as large registry studies. As for post hoc analyses, when the study included $a$ priori in the analyses plan the post hoc analysis and it was sufficiently powered, a CE 'B' was considered. If it was not the case, a lower $\mathrm{CE}$ was assigned ( $\mathrm{CE}$ ' $\mathrm{C}$ '). As for registry studies, at least a $\mathrm{CE}$ ' $\mathrm{C}$ ' level was attributed to registry studies (as other retrospective studies) of good quality and minimized risk of bias.

The treatment of unipolar MDE with mixed features according to DSM-5 was not considered in this guideline. When available, the authors considered results from studies in BDII and rapid cycling patients as well as information for efficacy or safety in children or old age.

\section{Safety and tolerability}

The CINP-BD-2017 (47) and the WFSBP guidelines (22) graded each medication in terms of safety and tolerability and considered these aspects in RG. The CANMAT-ISBD (39) task-force considered safety and tolerability concerns and risks of treatment emergent switch in mania/hypomania or depression in providing $\mathrm{RG}$ providing ratings reached by consensus (see Table $\mathrm{S} 2$ ).

The BAP (36) did not integrate safety and tolerability aspects with CE to provide RG. The Mood Disorder CPG (41) by the RANZCP did not consider safety and tolerability in the development of $\mathrm{RG}$, but the authors provided figures based on expert panel average ratings in which they graphically reported the ratings of tolerability for the different compounds.

Stahl and colleagues (43) reported about safety monitoring in their guidelines for the treatment of mixed depression, but it is not clear whether they integrated these aspects in the RG. They developed a table about the notable side-effects associated with MS and a figure for the relative tolerability of SGA (for sedation, weight gain, extrapyramidal symptoms) (see Table 4).

\section{Quality of the included guidelines}

The methodological quality assessment of included guidelines conducted by the two independent reviewers is reported in the Table S5. The quality scores of the specific domains for each guideline obtained by the two appraisers are reported in Table 5 . The quality substantially differed among the included guidelines. The AGREE II overall assessment rate ranged between $42 \%$ and $92 \%$. The BAP guidelines reached the highest AGREE II overall assessment rate.

\section{Discussion}

Summary of the treatment recommendations

The six guidelines included in this systematic critical review provided different recommendations for the treatment of mixed states or features of affective episodes. This could be the consequence of different approaches to rate the quality of available evidence. Four of six guidelines $(22,39,40,43)$ provided some grading of safety and tolerability, with treatment recommendations based on a combination of efficacy and risk/benefit ratio. We discussed each compound according to an operational definition of first- or second-line treatment recommendations as well as each treatment option is provided with the specification of the RG defined according to the original guidelines (see Table S2).

In general, the guidelines recommended starting the treatment with a medication fulfilling the highest criteria for efficacy and tolerability, that is SGAs in combination with lithium or valproate should be reserved for more severe presentations as first-line choice or as a subsequent step when another first-line medication failed. Mood-stabilizing medications generally reached evidence for the long-term treatment. All the guidelines agreed upon avoiding in mixed depression, in both BD and MDD, the use of AD or at least to combine a MS to the ongoing AD treatment.

Mania/hypomania with mixed features or manic mixed episodes. Oral antipsychotics, both dopamine antagonists and partial agonists, were the first-line treatments.

Olanzapine was recommended as first-line choice in the treatment of acute mania/hypomania with mixed features in all eligible guidelines with the exception of the last CANMAT/ISBD guideline (2). In particular, the WFSBP recommended it in monotherapy with $\mathrm{RG}$ ' 2 ' for manic symptoms but '4' for depressive symptoms during a manic mixed episode in the context of BD. The combination of olanzapine with a MS was recommended as firstline treatment in the RANZCP (II), by the CINP (2) and by the WFSBP (2 for valproate). Olanzapine in monotherapy was graded as ' 3 ' by the CINP. Despite the CE for olanzapine was rated 1 in the CANMAT/ISBD guidelines, both for the monotherapy and the combination treatment with 
Mixed states and features treatment review

Table 4. Comparison of the included guidelines: grading of compounds according to safety issues and tolerability

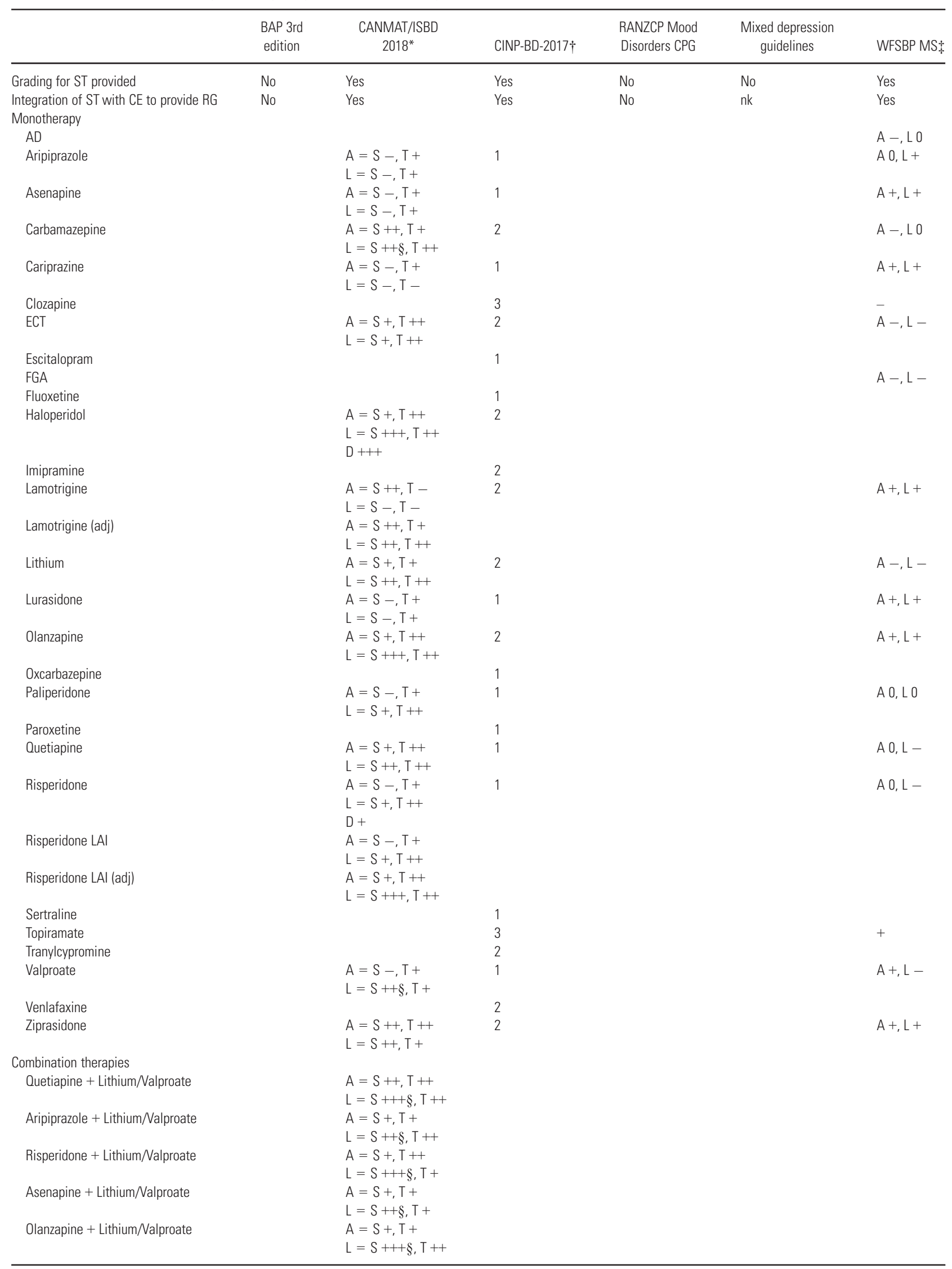




\section{Verdolini et al.}

Table 4. (Continued)

\begin{tabular}{|c|c|c|c|c|c|c|}
\hline & $\begin{array}{l}\text { BAP 3rd } \\
\text { edition }\end{array}$ & $\begin{array}{l}\text { CANMAT/ISBD } \\
2018^{*}\end{array}$ & CINP-BD-2017† & $\begin{array}{l}\text { RANZCP Mood } \\
\text { Disorders CPG }\end{array}$ & $\begin{array}{l}\text { Mixed depression } \\
\text { guidelines }\end{array}$ & WFSBP MS: \\
\hline Lurasidone + Lithium/Vaproate & & $\begin{array}{l}A=S+, T++ \\
L=S++\S, T++/+\end{array}$ & & & & \\
\hline Ziprasidone + Lithium/Vaproate & & $\begin{array}{l}A=S++, T++ \\
L=S++\S, T+\end{array}$ & & & & \\
\hline Lithium + Valproate & & $\begin{array}{l}A=S+, T++ \\
L=S++, T++\end{array}$ & & & & \\
\hline SSRIs/bupropion (adj) & & $\begin{array}{l}A=S-, T+ \\
L=S-, T+ \\
M / H++\end{array}$ & & & & \\
\hline Olanzapine-fluoxetine & & $\begin{array}{l}A=S+, T++ \\
L=S+++, T+ \\
M / H+\end{array}$ & & & & \\
\hline
\end{tabular}

A, acute treatment; AD, antidepressants; BAP, British Association of Psychopharmacology; BD, bipolar disorder; CANMAT, Canadian Network for Mood and Anxiety Treatment; $\mathrm{CE}$, category of evidence; CINP, International College of Neuropsychopharmacology; CPG, clinical practice guidelines; ECT, elettroconvulsive therapy; FGA, first generation antipsychotic; ISBD, International Society of Bipolar Disorder; L, long-term treatment; LAI, long acting injectable; MS, mixed states; nk, not known; RANZCP, Royal Australian and New Zealand College of Psychiatrists; RG, recommendation grades; SSRIs, selective serotonin reuptake inhibitors; ST, safety and tolerability; WFSBP, World Federation of Societies of Biological Psychiatry.

*CANMAT/ISBD 2018 Safety (S) and Tolerability (T) Concerns in Acute (A) and Maintenance (L) treatment and Risks of Treatment Emergent Switch in Mania/Hypomania (M/H) or Depression (D) consensus ratings: - Limited impact on treatment selection; + Minor impact on treatment selection; ++ Moderate impact on treatment selection; +++ Significant impact on treatment selection; nk not known.

†CINP-BD-2017 grading of treatment options according to safety issues and tolerability: from Level 1 (very good tolerability) to Level 3 (poor tolerability). Only most frequently used treatments reported.

\$WFSBP Mixed states Safety \& Tolerability (ST) rating for acute (A) and long-term (L) treatment: from '++' (best positive evidence) to '- - ' (strong negative evidence); "0" (equally advantages and disadvantages, or unknown).

$\S$ Caution in women of child bearing age.

Table 5. Quality scores of the six AGREE II domains and overall assessment

\begin{tabular}{|c|c|c|c|c|c|c|c|}
\hline Guidelines & $\begin{array}{c}\text { Domain } 1 \\
\text { Scope and } \\
\text { purpose }(\%)\end{array}$ & $\begin{array}{c}\text { Domain } 2 \\
\text { Stakeholder } \\
\text { involvement (\%) }\end{array}$ & $\begin{array}{c}\text { Domain } 3 \\
\text { Rigor of } \\
\text { development }(\%)\end{array}$ & $\begin{array}{c}\text { Domain } 4 \\
\text { Clarity of } \\
\text { presentation (\%) }\end{array}$ & $\begin{array}{c}\text { Domain } 5 \\
\text { Applicability (\%) }\end{array}$ & $\begin{array}{c}\text { Domain } 6 \\
\text { Editorial } \\
\text { independence (\%) }\end{array}$ & $\begin{array}{c}\text { Overall } \\
\text { assessment (\%) }\end{array}$ \\
\hline BAP 3rd edition & 97 & 67 & 82 & 92 & 40 & 83 & 92 \\
\hline CANMAT/ISBD 2018 & 89 & 58 & 60 & 81 & 35 & 71 & 67 \\
\hline CINP-BD-2017 & 69 & 64 & 66 & 78 & 25 & 96 & 58 \\
\hline RANZCP Mood Disorders CPG & 72 & 83 & 64 & 81 & 33 & 96 & 67 \\
\hline WFSBP Mixed states & 86 & 50 & 78 & 83 & 33 & 92 & 83 \\
\hline
\end{tabular}

BAP, British Association of Psychopharmacology; BD, bipolar disorder; CANMAT, Canadian Network for Mood and Anxiety Treatment; CINP, International College of Neuropsychopharmacology; CPG, clinical practice guidelines; ISBD, International Society of Bipolar Disorder; RANZCP, Royal Australian and New Zealand College of Psychiatrists; WFSBP, World Federation of Societies of Biological Psychiatry.

valproate, olanzapine was considered as a secondline treatment because of the safety and tolerability concerns. Olanzapine had probably the best positive evidence of all medication for the acute treatment of BDI patients with manic mixed episodes. Its high level of evidence in monotherapy was justified by results from two consecutive short-term RCT $(48,49)$ and four post hoc analyses, two analyzing subgroups of the above mentioned RCT $(50,51)$, a third post hoc analysis also including a Japanese study (52) and a post hoc analysis of the first acute three-arm RCT with asenapine vs. placebo or oral olanzapine (53). The evidence of olanzapine as add-on treatment was based on two $\mathrm{RCT}$, one evaluating the combination olanzapine- divalproex vs. divalproex monotherapy (54) and the other one comparing olanzapine + lithium/valproate vs. placebo + lithium/valproate (55), and one post hoc analysis of this second RCT (56). The combination of olanzapine with fluoxetine (OFC) was rated as ' 4 ' by the CINP (47) for inconclusive data for the manic component of mixed states. Despite this, the CINP graded OFC as the best choice in the presence of a full DSM-IV mixed episode (CINP fourth step recommendation).

Aripiprazole was recommended as a first-line choice in monotherapy by the BAP (I), by the WFSBP (3), for manic and depressive symptoms), by the CANMAT/ISBD (1) and in combination with MS by the RANZCP (II) and by the 


\section{Mixed states and features treatment review}

CANMAT/ISBD with valproate (1). The CINP rated aripiprazole in monotherapy as ' 3 '. The positive evidence for these recommendations was based on two RCT reported separate data for mixed patients $(57,58)$, on two RCT with a mixed sample of manic and mixed patients $(59,60)$, a negative acute study (61) and two underpowered RCTs (62, 63). As for the combination treatment, a RCT tested aripiprazole in combination/augmentation therapy in acute manic and DSM-IV mixed episodes but did not report separate data (64).

Paliperidone in monotherapy was a first-line choice for manic symptoms in acute mixed episodes by the WFSBP (3) on the basis of two different 3-week RCTs, the first one comparing efficacy in BD-I patients, including 171 mixed patients, of extended-release (ER) paliperidone with quetiapine and placebo (65). The second study compared three different dosages of ER-paliperidone (3 mg, $6 \mathrm{mg}$, and $12 \mathrm{mg}$ ) with placebo in patients with DSM-IV criteria for a manic or mixed episode (163 mixed episodes) (66). The CINP rated paliperidone as a second-line choice (3) for acute mixed episodes on the basis of the same studies. On the contrary, paliperidone in combination with lithium or valproate was not found to be superior to lithium or valproate monotherapy in a RCT including patients with a mixed index episode (67).

Other relatively new SGAs, such as ziprasidone and asenapine, were recommended for mania/hypomania with mixed features or manic mixed episodes but with conflicting RG among the guidelines. Ziprasidone was recommended as a first-line choice in combination with MS (II) by the RANZCP and as a second-line choice in monotherapy for manic and depressive symptoms (4) by the WFSBP, by the CINP (4), and the CANMAT/ISBD (2, for mixed mania and hypomania). This seems at odds with the fourth step recommendation in the clinical guidelines for the treatment of acute mania/hypomania in which the authors established that ziprasidone was between the two best choices in the presence of a full DSM-IV mixed episode. The use of ziprasidone in monotherapy was justified by a 3-week RCT (68) and a replication trial by Potkin and colleagues (69). Unfortunately, these studies did not report separated data for manic or mixed patients. A post hoc pooled analysis of these two RCT re-examined the data and showed improvement in both manic and depressive symptomatology (70).

Asenapine was a first-line choice in monotherapy according to the CANMAT/ISBD (1) and in combination with a MS (particularly valproate, CANMAT/ISBD 1) according to the RANZCP (II). It was rated as a second-line choice in monotherapy for the acute treatment of depressive symptoms (but not manic symptoms) of manic mixed episodes according to the CINP (3) and the WFSBP (4). The recommendations were based on a 3-week RCT vs. placebo and vs. olanzapine as active comparator (53), on three post hoc analyses (71-73) obtained using the pooled data of the previous RCT and an identical designed 3-week RCT (74) and from a 3-week RCT comparing asenapine 5 and $10 \mathrm{mg}$ bid with placebo (108 of 367 mixed patients) (75). Although results were conflicting for the efficacy of asenapine on the manic symptoms of the acute manic mixed state, significant improvement in the Montgomery Asberg Depression Rating Scale (MADRS) with asenapine but not with olanzapine was found, with asenapine differencing from the placebo group more in those patients with higher severity of depression (73). In addition, a further post hoc analysis of two acute RCT studies $(53,76)$ examined a subgroup of 98 patients with a mixed episode, showing significant decreases in MADRS scores greater in the asenapine group than in the placebo group (77). A further study assessed the combination of asenapine with lithium or valproate vs. placebo, but no separate analysis for mixed patients has been supplied (78).

Quetiapine was recommended as a first-line treatment only in combination/augmentation treatment for depressive symptoms (3) and as a second-line treatment for manic symptoms (4) during a manic mixed episode according to the WFSBP. The evidence for these recommendations was based on (i) a RCT in hypomanic patients with mixed features reporting that adjunctive quetiapine is superior to adjunctive placebo in improving overall severity and depressive symptoms, but not (hypo)manic symptoms (79), (ii) a retrospective study of BD patients reporting that the proportion of mixed patients responding to quetiapine was $77 \%$ (80), and (iii) a case report of a patient with mixed BD with psychotic features not responding to the combination of valproate, olanzapine, and fluoxetine, who after the replacement of olanzapine by quetiapine improved in the manic and psychotic symptoms (81). There are four positive studies supporting the efficacy of quetiapine up to $800 \mathrm{mg} /$ day for the treatment of acute mania in monotherapy $(65,82-84)$, but there was some concern about its efficacy against mixed episodes because of the following reasons: mixed patients were excluded $(82,83)$, a sub-analysis for quetiapine was not provided as it served only as an internal comparator (65) while in the 3-week RCT investigating extended-release quetiapine, quetiapine was not better than placebo for improving manic and depressive symptoms (84). A recent 


\section{Verdolini et al.}

study (85) evaluated the efficacy of quetiapine extended release vs. placebo as concomitant treatment to mood stabilizers in the control of subthreshold symptoms of BD but did not provide separate analysis for the mixed subgroup of patients.

The efficacy of cariprazine has been investigated in placebo-controlled studies (86-88) and in two pooled analyses $(89,90)$ reporting significant positive results for the mixed patients subgroup. Thus, the RG for cariprazine in monotherapy for the manic symptoms of an acute manic mixed episode is 4 (WFSBP).

Despite the good evidence for acute mania, risperidone did not reach high level of evidence in all the guidelines for the treatment of mixed manic states probably because of the risk of switch to depression and the limited number of mixed patients in the trials. The RANZCP recommended it as a first-line treatment only in combination with a MS (II) while both the CINP and the WFSBP recommended risperidone in monotherapy as a second-line treatment (CINP 3; WFSBP 4). Among the four RCT assessing the efficacy of risperidone $1-6 \mathrm{mg} /$ day for the treatment of acute manic and mixed episodes (91-93), one risperidone monotherapy trial including mixed patients $(n=9)$ did not show improvement of manic symptoms vs. placebo (91) as well as the randomized and doubleblind head-to-head comparison of risperidone vs. olanzapine (94) showed no significant differences in manic and depressive improvement. As for combination treatment, risperidone was compared with haloperidol or placebo, all in combination with lithium or valproate in mixed patients $(n=97)$, with no significant differences (95).

As for clozapine, the WFSBP task-force identified two small studies, a retrospective chart review examining clozapine in dysphoric manic patients as monotherapy or combined with lithium, valproate, or an AD (96) and an open-label study enrolling 10 adolescents with treatment-resistant manic/mixed episodes, prescribed with clozapine alone or in combination with a MS (97). In consideration of the issues existing with safety, the taskforce recommended clozapine as a second-line treatment (4) for acute manic mixed episodes in monotherapy or combination therapy (MS only). Similarly, the BAP recommended clozapine in combination with lithium or anticonvulsants as a first-line treatment in treatment-resistant patients.

FGA, in particular haloperidol, has been studied in mixed patients mainly as an active comparator for SGA in combination or not with MS $(95,98)$. No difference was found between olanzapine and haloperidol in monotherapy in terms of rates of symptomatic remission (Young Mania Rating Scale-YMRS scores) while in the comparison with risperidone in combination therapy with a MS (lithium or valproate), haloperidol + MS was not different from improvement observed with placebo + MS, leading to a recommendation grade of 4 for haloperidol in monotherapy for an acute manic mixed episode (WFSBP).

As for MS, only carbamazepine in monotherapy was a second-line treatment for both manic and depressive symptoms during a manic mixed episode according to the WFSBP (C) and the CINP (3). The evidence for these recommendations was based on two RCT comparing the acute efficacy of extended-release carbamazepine vs. placebo (99, $100)$ with improvement for manic (100) or for depressive symptoms (99). To assess the reliability of these results, a combined analysis pooling the data from both trials was conducted $(n=147)$ and demonstrated significant improvement of both manic and depressive symptoms in mixed patients (101). Carbamazepine in acute combination treatment has never been tested in mixed patients.

Valproate in monotherapy was recommended as a second-line treatment according to the CINP (3) and to the WFSBP (4, for manic symptoms). Limited data concerning the efficacy of valproate in acute mixed mania exist even because sometimes subgroup analyses in mixed patients have either not been conducted or properly reported (102, 103). A post hoc analysis of a 3 -week RCT (104) did not find any preferential effect for divalproex in classic vs. mixed manic patients (105). A small case series tested valproate in intravenous infusion in a very few sample of severely manic, mixed, or bipolar depressed patients (two manic, two mixed, one mixed with rapid cycling, two depressed) with improvement for the two mixed patients (106). No evidence exists for valproate in combination therapy for acute mixed states.

Lamotrigine in monotherapy has been recommended as a second-line treatment by the BAP (IV) probably on the basis of a possible extension to mixed patients of recommendation for manic patients. Nonetheless, no randomized controlled studies in manic mixed patients or subgroup analyses of studies in acute mania with lamotrigine have been reported.

Topiramate was rated as 5 (second-line) in monotherapy by the WFSBP. Topiramate has been tested in four RCTs in acute mania with negative results (107); hence, none of these RCT supplied a subgroup analysis for patients with mixed states. Evidence for topiramate in the treatment of acute mixed mania derived from one retrospective chart review (108), two open studies that used 
topiramate as adjunctive therapy in patients refractory to other treatments $(109,110)$ and a retrospective study evaluating adjunctive topiramate in adolescents (111), reporting partial improvement in manic mixed patients.

Oxcarbazepine and gabapentin have been evaluated by the WFSBP and estimated as a second-line treatment in combination therapy (4). As for oxcabazepine, mixed patients with an unsatisfactory clinical response to lithium have been administered with add-on oxcarbazepine with good clinical response in five of six mixed patients (112). Gabapentin has been tested in monotherapy in a 8-weeks RCT in dysphoric mania (113) with superiority of gabapentin to carbamazepine in mania ratings and to lamotrigine in depression ratings as well as important shortcomings in design and reporting limited the reliability of the results. Gabapentin has been tested in five open-label studies as adjunctive treatment (114-118) with improvement in manic $(114,116,117)$ or in depressive symptoms $(115,117,118)$.

Lithium lacked of specific evidence for the treatment of acute manic mixed episodes. No difference in treatment efficacy between lithium and placebo was found in a retrospective analysis (105) of a randomized, double-blind study on depressive mania (104). Lithium has also been studied as an add-on treatment of different SGA vs. placebo, but there was no placebo comparison for the lithium treatment $(55,56,67)$.

Electroconvulsive therapy (ECT) was considered as a second-line treatment (BAP IV, RANZCP III, WFSBP 4) for both depressive and manic symptoms of a manic mixed episode. The evidence for ECT was based on a case series suggest that ECT is effective in the treatment of acute mixed episodes (119-121), on a retrospective study on 20 manic-depressive mixed patients (122) and other observational studies (123-125). Even though there was no RCT evaluating the efficacy of ECT relative to other treatments in mixed affective states, ECT has been found to have reasonable evidence for its safe and effective use in manic mixed patients, particularly in those patients refractory to pharmacotherapy.

Finally, the treatments that the guidelines advised to avoid were AD monotherapy, lithium in monotherapy (CINP 5), antipsychotics in monotherapy, particularly asenapine for manic symptoms (evidence from post hoc analysis is negative for asenapine monotherapy to be effective against acute manic symptoms, WFSBP category E, CINP 5), paliperidone for depressive symptoms (WFSBP category E, CINP 5), quetiapine for both manic and depressive symptoms (WFSBP category
E, CINP 5) and combination treatment of FGA (haloperidol, WFSBP category E, CINP 5), SGA (risperidone, WFSBP category E, CINP 5; paliperidone, WFSBP category E), or other treatment, that is, celecoxib (CINP 5).

Depression with mixed features or depressive mixed episodes. Even though depression with mixed features or depressive mixed episodes is already well-known conditions, they are relatively new diagnostic entities and only recently research on their specific treatment has been conducted and recommendation guidelines have been developed.

There are currently no psychotropic agents approved by FDA and EMA for the treatment of depression with mixed features. No MS is actually approved for use in depression of any kind except lamotrigine (43). In general, AD treatment in monotherapy should be avoided $(39,43)$.

SGAs are the only psychotropic agents that have been specifically tested for the treatment of depression with mixed features, but not all of them have demonstrated efficacy in bipolar depression. As a consequence, caution is needed when extrapolating recommendations from studies in bipolar depression for depression with mixed features (unipolar or bipolar).

Ziprasidone in monotherapy for acute depressive mixed episode was rated as a first-line treatment in the Stahl et al. guidelines (1) and by the WFSBP in combination with treatment as usual (3) but as a second-line treatment according to the CINP (4). The evidence for these recommendations was based on a 6-week, randomized, placebo-controlled trial on patients suffering from BDII or MDD during a MDE (126). Ziprasidone was added to the TAU and compared to placebo. Mixed BDII and MDD patients on ziprasidone presented higher response and remission rates, with more benefit in BDII than in MDD, and reduction in depressive symptoms but not in manic ones. A post hoc analysis of this study was conducted to assess other predictors of response, but no significant effect was found (126).

Olanzapine was rated as a first-line treatment both in monotherapy (RANZCP I, Stahl et al. guidelines 2) and in combination with MS (CINP 2, RANZCP II with valproate, Stahl et al. guidelines 2) or AD (RANZCP II, Stahl et al. guidelines 2 first-line with fluoxetine). Olanzapine monotherapy (WFSBP 4, CINP 3) or the combination olanzapine+fluoxetine (CINP 4, CANMAT/ISBD 2) was rated as a second-line treatment according to WFSBP, the CINP, and the CANMAT/ISBD. The evidence was conflicting and was based on a post hoc analysis (127) of a 8-week RCT on BD-I 


\section{Verdolini et al.}

patients during a depressive episode treated with placebo, olanzapine, or OFC (128). Compared to placebo, both olanzapine and OFC were efficacious treatments of bipolar depression with mixed features, with OFC being the most efficacious treatment. A pooled analysis (52) of this study, together with a second RCT on BDI patients with depression (129), was conducted. Olanzapine was significantly better than placebo in reducing depressive symptoms, irrespectively of the presence of concurrent manic symptoms.

Lurasidone was considered a first-line treatment in monotherapy or in combination by Stahl and colleagues and by the CANMAT/ISBD (1), and as a second-line treatment in monotherapy according to the WFSBP (4). Lurasidone was evaluated in the treatment of bipolar mixed depression with a placebo-controlled monotherapy RCT (130), a placebo-controlled combination RCT (131), and a second controlled combination treatment RCT enrolling MDD patients with mixed features in which lurasidone did not separate from placebo (132). A post hoc analysis of the monotherapy RCT was conducted on patients with mixed manic features (133), and treatment with lurasidone was associated with significantly greater reductions in MADRS scores with possible capabilities of lurasidone to prevent treatment emergent affective switch (TEAS). Lurasidone was the only compound to have been investigated for the treatment of MDE with MFS in the context of MDD. A randomized, double-blind, placebo-controlled study (134) and three post hoc analyses of the same RCT have been conducted specifically in MDD patients with mixed features. The first post hoc analysis (135) evaluated the efficacy of lurasidone in treating MDD with mixed features including irritability, with significant improvement at week 6 of MADRS score in both patients with and without irritability and in specific YMRS items (irritability and disruptive aggressiveness). The second post hoc analysis (136) evaluated the efficacy of lurasidone in treating patients with MDD with mixed features and mild and moderate-to-severe levels of anxiety, with significant changes in 6 weeks in MADRS total score for patients with both mild or moderate-to-severe anxiety and changes in HAMA total score. The third post hoc analysis (137) found lurasidone to be effective in treating postmenopausal MDD patients with mixed features.

Even though quetiapine (even in the extendedrelease formulation), asenapine, aripiprazole, and cariprazine were considered a first-line treatment according to the RANZCP (quetiapine) and to the Stahl and colleagues' guidelines (1) in monotherapy and in combination with an AD (RANXCP II for quetiapine) or a MS (Stahl and colleagues' guidelines), and a second-line treatment according to the CINP (aripiprazole, asenapine CINP 3) and to the CANMAT/ISBD (3), the WFSBP did not find any suitable study on quetiapine, asenapine, aripiprazole, and cariprazine in acute depressive mixed episodes to rate the evidence.

The RANZCP and the Stahl and colleagues' guidelines proposed MS, particularly valproate, lamotrigine, and lithium, alone or in combination, as possible first-line treatment for acute depressive mixed states. Carbamazepine was rated as a second-line treatment by the CINP (3), by the Stahl and colleagues' guidelines, and by the WFSBP (4, monotherapy for depressive symptoms). Nonetheless, the WFSBP did not find any suitable study to rate the evidence for lithium, lamotrigine, and valproate. As for carbamazepine, no RCT exists on the treatment for acute depressive mixed states but a case series (138) of carbamazepine monotherapy in bipolar depression $(n=9)$ reported improvement of Hamilton Depression Rating Scale (HAMD) depressive symptoms.

$E C T$ was recommended as a second-line treatment in combination with MS (WFSBP 4, Stahl and colleagues' guidelines 3 ) on the basis of subanalyses of observational studies. The AgitatedIrritable Mixed-Depression group in the study by Medda and colleagues (121) was found to have the greatest improvement from ECT (139).

Other recommended second-line treatments by Stahl and colleagues were the combination of MS or SGA with bupropion, SSRI, or MAOI.

Finally, paliperidone (CINP), $A D$ in monotherapy (WFSBP, Stahl and colleagues' guidelines), topiramate (Sthal and colleagues guidelines), risperidone, haloperidol, and celecoxib in combination with MS (CINP), carbamazepine + olanzapine, or risperidone (Stahl and colleagues' guidelines) are not recommended treatments in acute depressive mixed states.

Maintenance treatment. MS and SGA were rated as efficacious treatment in the long-term management of mixed states.

Lithium, valproate, and olanzapine were the treatments that were considered as effective in the prevention of a new mixed episode after an acute manic or depressed index episode, with scant and conflicting evidence. Olanzapine and lithium were rated as a second-line treatment in preventing mixed recurrence according to the WFSBP (5) while the BAP rated lithium as a first-line treatment against mixed relapse. Lithium (WFSBP 5, BAP I) and valproate (WFSBP 3) were significantly associated with a reduced rate of admissions 
because of a mixed episode in a big observational Swedish registry study (140). In a re-analysis (141) of an head-to head comparison RCT olanzapine vs. lithium (142), olanzapine had a significantly lower risk of symptomatic mixed episode relapse/ recurrence than lithium. Valproate was the only compound rated as a first-line treatment in the prevention of a new mixed episode on the basis of the results of a meta-analysis (143) that includes a 20 month maintenance RCT comparing valproate and lithium without no placebo-arm (144) showing no statistical difference between valproate and lithium in preventing a mixed episode. The study was difficult to rate because it was evaluated post hoc in the meta-analysis and lithium might be not the ideal standard comparator. Negative evidence (E) was reported for aripiprazole (after a manic index episode), carbamazepine, lamotrigine, quetiapine in preventing a new mixed episode.

In the prevention of episodes of any polarity after a mixed index episode, lithium in monotherapy or in combination was considered a first-line treatment (BAP I, WFSBP 3) on the basis of the results of retrospective studies (145-148), maintenance RCT (149), and subanalysis of maintenance RCT (150). Nonetheless, valproate was found to be even more effective than lithium (RANZCP) in the prevention of new affective episodes in a post hoc analysis (151) on dysphoric mania $(n=123)$ of a 12-month maintenance study comparing valproate, lithium, and placebo (152). These results were at odds with those of an observational cohort study (146) with linkage of nationwide registers in which the overall rate of hospital admissions was significantly increased for valproate compared with lithium in patients with a mixed index episode. Because of this conflicting evidence, valproate was rated as $E$ (negative evidence) according to the WFSBP and consequently not recommended in the prevention of episodes of any polarity. Carbamazepine was poorly studied as a maintenance treatment for patients with a mixed states, and the available evidence was difficult to rate because of limitations in the study design. In fact, the efficacy of carbamazepine extended-release as maintenance treatment was evaluated in bipolar patients during a manic or mixed episode but the data of the separate analysis for the mixed subgroup were only reported for depressive symptoms. Carbamazepine treatment maintained the significant decrease of depressive symptoms, but the evidence is not confirmative in the absence of reported numbers for relapses (153).

Olanzapine in monotherapy was recommended as a first-line treatment (CINP 2, WFSBP 3 ) in the prevention of any type of affective episodes after an acute mixed episode on the basis of a RCT for maintenance treatment comparing olanzapine vs. placebo (154) and its post hoc analysis (155). In fact, olanzapine-treated patients showed significantly lower rates of symptomatic relapse of any kind. No definite data are available for the combination with lithium or valproate as the only RCT conducted on olanzapine + MS did not report separate results for mixed patients (156). Even though the evidence was quite good, the second-line recommendation by the WFSBP was mainly because of profound concerns about weight gain and longterm metabolic effects of olanzapine in the longterm.

Quetiapine was considered as a first-line treatment both in monotherapy (WFSBP 3, for manic and for any type of episode prevention; CANMAT/ISBD 1) and in combination with lithium or valproate (WFSBP 2, CANMAT/ISBD 1, for manic, depressive, and any type of episode prevention). The evidence for these recommendations was based on a large relapse and recurrence prevention RCT (147) with a wide mixed patients subgroup ( $n=223)$, on two identically designed RCT comparing quetiapine vs. placebo + lithium or valproate $(157,158)$, and a post hoc analysis of the mixed patients included in the two previous RCT that confirmed the efficacy of quetiapine in the long-term treatment (159).

As for ziprasidone, it was a second-line treatment for manic relapse in monotherapy (WFSBP 4) on the basis of a monotherapy (68) and a combination RCT (160).

Aripiprazole was recommended as a first-line strategy in the prevention of episodes of any polarity in combination treatment with MS (CINP 2). The WFSBP task-force rated aripiprazole as a second-line strategy for depressive recurrence in combination with lamotrigine (WFSBP 4) but reported negative evidence (E) for aripiprazole + MS (lithium or valproate) in the prevention of any episode. The evidence for these recommendations is based on a post hoc analysis (161) of a 52-week maintenance combination study of aripiprazole + MS vs. placebo (162) that found no significant advantage of aripiprazole for the group of mixed patients for time to any relapse, a small maintenance RCT, with no separate outcomes reported for mixed patients (163) and a post hoc interaction analysis of a 52-week RCT testing lamotrigine + aripiprazole vs. lamotrigine + placebo (164) showing that time to relapse to a depressive episode was significantly longer with the aripiprazole combination compared with the placebo. Data on the maintenance treatment of aripiprazole in monotherapy are not available. 


\section{Verdolini et al.}

Risperidone was recommended as a second-line treatment (WFSBP 4) in combination/augmentation therapy after a mixed index episode in preventing episodes of any polarity on the basis of two open-label studies in which risperidone added to lithium or valproate supplied evidence for acute efficacy maintained long-term (6 months) (165) and presented significant improvement of both manic and depressive symptoms over 24 weeks (166).

Even though little is known about the impact of acute ECT on the long-term outcome of bipolar patients, the WFSBP task-force recommends ECT as a second-line maintenance treatment in combination with a MS (WFSBP 4) on the basis of a case series (167), a prospective naturalistic study (168) and a naturalistic study on rapid-cycling patients unresponsive to prophylactic MS (169).

As for lurasidone, it was not possible to rate the evidence for the long-term treatment because in the three studies aimed at investigating the efficacy of lurasidone vs. placebo including mixed patients (170-172), no separate outcome has been reported for this group. A recent post hoc analysis evaluating remission and recovery associated with lurasidone in the treatment of MDD with mixed features (173) reported patients treated with lurasidone significantly achieved recovery compared to placebo after 6 weeks of treatment, but this study was not included in the considered guidelines.

The evidence for long-term treatment of AD was scant, and The International Society for Bipolar Disorders (ISBD) task-force discouraged the use of AD use in BD because of safety reasons (174). Stahl and colleagues underlined that a small minority of patients presenting a depressive episode with mixed features could improve with a long-term treatment that includes an AD, but only as an adjunct to MS.

\section{Comparison of the different guidelines}

As a general rule, all the guidelines included were created without any financial support from pharmaceutical companies and experts of the task-force were selected according to their expertise. Guidelines have been developed by multidisciplinary teams involving experts from different countries to facilitate their applicability around the world.

The BAP guidelines were at their third revision and the CANMAT guidelines at their 4th update, while the other guidelines included in this critical review were at their first edition.

The BAP guidelines, the RANZCP Mood Disorders CPG, the CINP-BD-2017, and the CANMAT guidelines were primarily aimed at providing recommendations for the treatment of $\mathrm{BD}$ or mood disorders in general while the WFSBP guidelines and the Stahl and colleagues' guidelines focused on mixed states or mixed features. The WFSBP had their primary scope on the acute and long-term treatment of manic or depressive mixed episodes in BDI disorder as categorized in DSMIV and DSM-5 while the Stahl and colleagues' guidelines were developed to help in the recognition and management of a MDE with mixed features in the context of BD or MDD in reference to DSM-5 criteria. Stahl and colleagues' guidelines did not report separated treatment strategies for $\mathrm{BD}$ and MDD with MFS but simply referred to depression with mixed features or mixed depression.

Different aims corresponded to different methods. As a consequence, the guidelines differed in their methodology.

As for the literature search methodology, the articles included in each guideline varied according to the specific purpose of the different task-forces. The methodology of the BAP guidelines did not allow for a systematic review of all possible data from primary sources and publications identified up to December 2015. Similarly, the Stahl and colleagues' guidelines as well as the CANMAT/ISBD update 2018 did not provide a time limitation or information about the literature search. The RANZCP task-force did not report the time limitation of the literature search but assessed that the same search was repeated regularly between April 2013 and October 2015. The CINP guidelines have been developed following the PRISMA method, and a systematic search was conducted up to March 25, 2016. Finally, the WFSBP task-force conducted the original search on May 29, 2013, and it was updated on March 12, 2017.

The methodology of the definition of category of evidence and the recommendation grades varied across the included guidelines. The BAP guidelines were the most elaborated and used the GRADE approach to justify the quality standard of recommendations, including both RCT and observational studies to provide more objective and highly clinically relevant recommendations. On the contrary, the process used to gather and synthesize the evidence and the methods to formulate the recommendations in the Stahl and colleagues' guidelines, which were more clinical-expertise oriented than evidence-base oriented, was not well stated, as confirmed by the low-quality score of the AGREE II domain 3.

The first main distinction across guidelines came from the different weight given to post hoc analyses, as they play a prominent role in studies 
including mixed patients. According to the WFSBP, when a post hoc analysis has been included $a$ priori in the analyses plan and is sufficiently powered, a CE 'B' could be considered. On the contrary, the CINP college rated post hoc analyses as level 3 of the efficacy grading with discrepancies in the recommendation grades between the guidelines. No specific grading for post hoc analyses was provided by the other guidelines.

In addition, both the BAP and the WFSBP task forces decided to accept registry observational studies in their evidence categories to take in consideration the valuable information about the 'real-world' effectiveness and acceptance of treatment modalities that these studies could provide, with different grades of efficacy on the basis of the quality of the studies. The CANMAT/ISBD guidelines included health system administrative data but rated them as CE 3 .

Another point is the importance given to metaanalyses. All the guidelines, WFSBP and CINP guidelines excluded, define the presence of positive results from meta-analyses as full evidence for the efficacy of a determined compound (not clear in the Stahl and colleagues' guidelines). Particularly, the CANMAT/ISBD task force differentiated the evidence from meta-analysis on the basis of the narrow or wide confidence intervals (CE 1 or 2 respectively). On the contrary, the WFSBP taskforce did not use the results of meta-analyses as evidence of the same level of the results from single RCT fulfilling inclusion criteria. Meta-analyses were only used in the case of existing negative studies to grade the evidence in the case of studies showing non-superiority to placebo or inferiority to comparator treatment. The members of the CINP college included meta-analyses in the evidence they graded but considered them as a second level of the efficacy grading, prioritizing good research-based evidence supported by at least 2 placebo-controlled studies of sufficient magnitude and good quality.

\section{Clinical messages}

According to the guidelines included in this critical review, the acute treatment of both depressive and manic/hypomanic mixed episodes is based on SGA. Lithium and valproate as well as SGA were found to be efficacious in the prevention of new affective episodes. The choice between the different compounds should be made on the basis of clinical issues that arise from these recommendations.

Particularly, recommendation grades (RG) for each compound have been generally derived from safety and tolerability aspects integrated with $\mathrm{CE}$, with few exceptions. Indeed, the BAP, the Mood CPG, and the Sthal and colleagues' guidelines did not report a grading for safety and tolerability.

SGA were the psychotropic agents that have been generally considered as first-line choice in the treatment of acute mania/hypomania or depression with mixed features in all the guidelines. The compounds identified as SGA differed widely between them, mainly in terms of safety and longterm tolerability (175), particularly in the maintenance treatment, resulting in a downgrading of the $\mathrm{RG}$, especially when making a distinction between RG 1 and 2 (i.e., olanzapine).

Another important clinical aspect in guiding the choice of maintenance therapy should be the polarity index of the different compounds (176). SGAs such as risperidone, aripiprazole, ziprasidone, olanzapine, quetiapine, and other compounds such as lithium have a polarity index superior to 1 which means that they are better preventing mania than depression. Only lamotrigine and lurasidone have a polarity index under 1 (and are, thus, better suited for patients with depressive predominant polarity) (177). These general considerations can get even more complicated when it comes to mixed states for the presence of intertwined opposite symptoms that may change the antimanic or depressive prophylactic efficacy. Pharmacotherapy of mixed states is challenging because antipsychotics used to treat manic symptoms, and AD could potentially deteriorate symptoms of the opposite polarity (13). According to the polarity index (177), lamotrigine and lurasidone might have a depressive preventive efficacy in $\mathrm{BD}$ maintenance treatment, but currently, the evidence is still lacking for the long-term treatment of mixed episodes. Only lithium, olanzapine, and quetiapine in monotherapy had robust evidence for the prevention of new depressive episodes in the guidelines included in this critical review. As a consequence, the prevention of depressive recurrence is still a challenging point, mainly because of the lack of evidence for the preventing effect of SGA, MS, and antiepileptic compounds.

The scarcity of researched treatment options is frequently associated with a clinical management that often relies on AD (178). The International Society for Bipolar Disorders (ISBD) Task-force Report on AD use in Bipolar Disorders (174) recommends avoiding AD use in BD patients with a history of past mania, hypomania, or mixed episodes emerging during previous AD treatment and that should be avoided in patients with high mood instability or with a history of rapid cycling. Despite this, there is still a wide use of AD in the real-world clinical psychiatry (179-181) despite the 


\section{Verdolini et al.}

weak evidence for the efficacy and safety of AD in BD. The EMBLEM study reported that more AD maintenance use was seen in patients with mixed episodes (179). The two main consequences in the use of $\mathrm{AD}$ in patients with mixed features are the risk of switching in mania and the risk of suicide. A recent post hoc analysis of the BRIDGE-II-MIX study (182) underlined that AD-induced hypomania/mania patients with MDD reported higher rates of treatment resistance, mood lability, and irritability following treatment with $\mathrm{AD}$ and were mainly represented in the groups of depressed patients with mixed features and among BD patients. As for the risk of suicide, several studies found an association of lifetime mixed episodes, higher rates of $\mathrm{AD}$ use, and increased risk of suicide behaviors (183-185). It is for this reason that the ISBD task-force recommended that AD in BD patients should be prescribed only as an adjunct to mood-stabilizing medications (174). As underlined by Stahl and colleagues, AD may protect from depressive recurrences in a small minority of patients with mixed features, both in bipolar and in unipolar patients $(43,186)$, especially if prescribed in combination with antimanic agents.

The idea is that MDE with mixed features should be viewed differently from unipolar MDE without mixed features in terms of natural history, clinical outcome, and treatment (5). Mixed features in MDD have been seen to be related to high recurrence (187) and other detrimental clinical correlates, such as higher risk of suicide (188), obesity (189), and borderline personality disorders comorbidity (190) in recent BRDGE-II-Mix post hoc analyses. Furthermore, nearly a quarter of patients suffering from MDD may convert to BD (191). According to the findings of two recent meta-analyses $(191,192)$, the transition from MDD to BD was predicted by clinical features such as family history of $\mathrm{BD}$, earlier age of onset of depression, the presence of psychotic symptoms $(191,192)$, the number of depressive episodes, the resistance to $\mathrm{AD}$, the severity of depression, the prevalence of chronic depression (192) and, interestingly, subthreshold manic symptoms during a MDE (191). Hence, the MFS may serve a clinically relevant role as a 'warning sign' for bipolarity, in spite of its limitations.

The fact that certain antipsychotics or MS should be given as first-line in the acute and longterm treatment of mixed MDE rather than AD monotherapy should lead to a paradigm shift in the 'safe' and 'comfortable' use of $\mathrm{AD}$, preferring the more 'dangerous' and 'uncomfortable' compounds such as SGA and MS (193). Indeed, psychiatrists are called to choose between over- diagnosis of MDE with MFS better treated with SGA or missing the diagnosis of mixed symptoms and treating the patient with $\mathrm{AD}$ with consequent treatment resistance of harmful side-effects (suicide, switches into hypo/mania) (194). In line with this aspect, the most important virtue of the DSM-5 MFS could be the higher sensitivity than the DSM-IV-TR mixed episodes classification in the identification of the orthogonal aspects of suicidality (i.e., suicidal ideation, suicide attempts) (2). As mixed depressive episodes are three times more common in BDII compared to MDD, the possibility to apply the MFS even to BDII would allow a more accurate identification of suicidal tendencies $(2,9)$.

Finally, there is growing evidence suggesting that mixed symptoms commonly contribute to poor treatment response with implications of potentially less satisfactory response to treatment (195-197) (Level IV BAP). Clozapine in combination treatment with MS was found to be superior to TAU in treatment-resistant patients during a mixed manic episode. Even though ECT is often a neglected treatment option carrying the burden of unfavorable media portrayal and wrong general beliefs and thus frequently used as a last-resort-treatment for severe bipolar patients (178), it has been found to have reasonable evidence for its safe and effective use in manic mixed patients, particularly in those patients refractory to pharmacotherapy.

\section{Methodological limitations}

This critical review has limitations, mainly depending on the methodological issues of the included guidelines.

The guidelines included in this critical overview reported on the treatment of manic/hypomanic and depressive episodes with mixed features or mixed states, using different diagnostic criteria (DSM-IV or DSM-5) to define mixed symptoms.

All the guidelines included in this critical review lack of strength in the applicability domain, which evaluate the resource implications of applying the guideline, the barriers, and facilitators to implementation and the strategies to improve uptake (34). The guidelines included, except from the BAP guidelines, did not report about monitoring or auditing criteria; consequently, it will be impossible to rate improved outcomes for patients treated in accordance with these guidelines. Ideally, guidelines should evaluate the role of specific pharmacological interventions in the treatment of mixed states considering efficacy and real-world effectiveness (31) but the guidelines included did not report 
about facilitators and barriers to their application or on the resource implications of the applicability of their recommendations.

Another common methodological flaw of the studies included in the guidelines considering treatment for mixed states was that the response of mixed patients to pharmacological agents had been extrapolated from post hoc or pooled analyses of RCT that have enrolled both pure and mixed manic patients, assuming a comparable response to treatment for both subgroups of patients (22).

Given the several criticisms arisen toward the different classifications of mixed states and mixed features in the different editions of the DSM, many researchers tried to provide alternative definitions and to adopt different criteria for diagnosis mixed presentations (198-201). As there is not a consensus regarding the definition of mixed states and because of the major concerns about the DSM-5 MFS, it is not surprising that there is a paucity of evidence examining treatment outcomes and mixed features have been assessed post hoc and with a cross-sectional design in the most recent literature (13). Indeed, only few of the RCTs included in the guidelines considered the DSM-5 MFS as the primary outcome of treatments for bipolar hypomanic, manic, and depressive episodes.

Another further major flaw of the literature is that mixed depressive patients are not usually reported in depression RCT (24). Furthermore, the evidence about the treatment of MDD with MFS is still scant and limited to lurasidone (134-137, 173). Accordingly, the guidelines included in this systematic review did not differentiate the treatment for MDE with MFS in the context of BD or MDD (43).

One of the most important limitations of guidelines is their excessive reliance on evidence-based data resulting from RCT, which bring important limits in their design such as poor generalizability of the results and the sponsor bias. Interestingly, only the BAP guidelines considered observational studies and independent trials. These studies have methodological limitations and lower internal validity than RCTs, but they are much more generalizable and may have less sponsor bias $(36,202)$. Indeed, a recent systematic review assessing the effectiveness of maintenance treatment of lithium vs. other mood stabilizers highlighted that RCTs are affected by methodological limitations, specifically in the case of comparative maintenance trials (202).

Few methodological limitations of the systematic review itself were worthy to be mentioned. In the attempt to be as rigorous as possible, the authors decided to consider as eligible only international guidelines resulting in only six guidelines meeting all the inclusion criteria, with the exclusion of national guidelines. Despite this, the scientific value derived by the international teams with experts from different countries of the included guidelines could insure their applicability around the world and not only on a national basis. Finally, as the quality methodology of the included guidelines was assessed with the AGREE II tool, the authors of this systematic review could not completely exclude that the findings may be influenced by the interpretation and ranking of the evidence by the two reviewers (NV and DHM). Nonetheless, the two reviewers successfully completed the training modules of the AGREE II tool and undertook independent appraisals for each of the included guidelines, warranting the rigor of the methodology of this systematic critical review and the reliability of its findings.

\section{Future perspectives}

From a diagnostic point of view, a dimensional approach defining the most parsimonious clinical model aimed at understanding the specificity of the relationship of mixed features within the context of bipolar vs. unipolar disorders is needed. The clinical presentations could be best characterized along a number of domains, in which cognition and energy play critical roles in mixed presentations in terms of attention, memory, motivation, drive, and behavioral activity that should be better understood and rated. Mood could also be assessed, with a focus on specific symptoms rather than symptom clusters or diagnostic syndromes, with a differentiation between spontaneous mixed states and those induced by treatment (13). Clinical mixed presentations should also be differentiated by other course and comorbid specifiers, such as anxious distress or atypical symptoms. In addition, clinicians should assess the clinical aspects of mixed presentations not only evaluating the single affective mixed episode but also trying to understand the longitudinal course of affective disorders presenting with mixed components.

A better understanding of the neurobiology of mixed states will be necessary to develop more effective treatments (203). Indeed, it is not completely clear which are the clinical characteristics of patients experiencing mixed features that can firmly predict treatment response or side-effects. Genetic and neurobiological research could help identifying new compounds, profiles of response, and safety/ tolerability concerns in mixed patients in the perspective of a personalized pharmacological treatment for the different subtypes of mixed states. 


\section{Verdolini et al.}

Future research should try to overcome the limitations of the current inadequate amount of data on mixed states treatment (25). One of the most important problems in recommending treatments in mixed states is the lack of evidence for many compounds that could be possibly used in the acute and long-term treatment of mixed states (i.e., RCT on long-term treatment with asenapine, lurasidone, or lamotrigine in monotherapy for mixed patients). Clinical well-designed adequately powered double-blind placebo-controlled studies assessing the efficacy, safety, and tolerability of psychotropic agents in mania, hypomania, or depression with mixed features are needed. Compounds that are already known to be effective (i.e., olanzapine) as well as controversial options (i.e., carbamazepine, lamotrigine) deserve a better understanding. In addition, large observational studies are needed because of the possibility to identify 'real-world' clinical variables associated with the treatment of mixed states.

A specific focus should be the long-term treatment as it represents an often ignored but fundamental topic in the treatment of the mixed presentations. Particularly, many treatment options, including 'old' well-known medications such as carbamazepine, lamotrigine, or even relatively 'new' compounds such as asenapine, lurasidone, and paliperidone, have not been studied in depth in mixed patients the long-term.

As psychotherapies and psychoeducation are important and well documented techniques for improving compliance and resilience against mood changes in the treatment of bipolar disorder, their integrative role and established component of treatment should be better investigated in mixed affective presentations. Indeed, psychotherapeutic trials showed efficacy in bipolar depressive symptoms and in maintenance treatment, as add-on treatment to medication in both cases, but no psychotherapy has yet provided an alternative strategy for management of patients in acute manic phases (36). To the best of our knowledge, no study reported on psychotherapy in acute mixed patients so far. Only one study has been published on recurrence prevention of mixed episodes, with adjunctive psychoeducation that was found to be effective in delaying the time to a new mixed episode (204).

In conclusion, treatment guidelines are a useful tool to guide the management of acute and longterm treatment of affective mixed clinical presentations together with professional knowledge and clinical judgment, in the attempt to orientate clinical practice toward evidence base. In mixed states, despite their heterogeneity, all guidelines agree with interrupting an ongoing $\mathrm{AD}$ monotherapy and adding mood-stabilizing medications. Olanzapine might have the best evidence for the treatment of acute mixed hypo/manic or depressive states as well as maintenance treatment of mixed presentations in preventing new mixed episodes or affective episodes of any polarity. Aripiprazole and paliperidone in monotherapy seemed to be effective alternatives in the treatment of acute hypo/manic mixed states while lurasidone and ziprasidone (in combination) revealed as promising SGA substitutes in the treatment of acute depressive manifestations without the adverse effects load of olanzapine. As for the maintenance treatment, valproate was recommended in the prevention of new mixed episodes while lithium as well as combination treatment of quetiapine was rated as effective in preventing affective episodes of all polarities. Finally, clozapine and especially ECT are options to consider in treatment-resistant presentations. These findings should be kept with caution as the available evidence is still scant. For example, to support the superiority of olanzapine, large comparative RCTs should be conducted assessing its efficacy vs. other compounds and not only vs. placebo.

The problem of which guideline is better is a difficult one. The included guidelines showed high scientific standards and good methodologies with some differences between the guidelines mentioned in this critical review that could orientate the clinicians in the choice of which guideline to follow. According to methodological robustness, the quality of the BAP guidelines was undoubtedly the best, reflected by the highest AGREE II overall assessment rate among the included guidelines. Nonetheless, the treatment of mixed states could not be longer derived from the treatment of manic or depressive episodes in the context of bipolar disorder because of the new DSM-5 mixed features specifier which is also applicable to unipolar depression. In this sense, the WFSBP Guidelines for the Biological Treatment of Bipolar Disorders: Acute and Long-term Treatment of Mixed states in Bipolar Disorder represented the most focused guidelines on the treatment of mixed states, with the added value of a similarly good global quality. Conversely, the Stahl and colleagues' guidelines were the first one to address depression with DSM5 mixed features, although concern was raised for the rigor of development and the overall assessment rate. The CANMAT/ISBD guidelines, finally, are the most recent and up-to-date. In clinical practice, treatment guidelines are a suitable framework to start thinking on the management strategy for a particular patient, but decisions need 


\section{Mixed states and features treatment review}

always to be individualized in the growing context of personalized medicine.

\section{Acknowledgements}

The authors thank the support of the Spanish Ministry of Economy and Competitiveness integrated into the Plan Nacional de I+D+I and co-financed by the ISCIII-Subdirección General de Evaluación and the Fondo Europeo de Desarrollo Regional (FEDER); the Instituto de Salud Carlos III that supported this work through a 'Río Hortega' contract (CM17/ 00258) to NV); the CIBERSAM (Centro de Investigación Biomédica en Red de Salud Mental); the Secretaria d'Universitats i Recerca del Departament d'Economia i Coneixement (2017 SGR 1365); and the CERCA Programme/ Generalitat de Catalunya. This report represents independent research partially funded by the National Institute for Health Research (NIHR) Biomedical Research Centre at South London and Maudsley NHS Foundation Trust and King's College London. The views expressed are those of the authors and not necessarily those of the NHS, the NIHR, or the Department of Health.

\section{Declaration of interest}

Dr. Norma Verdolini is funded by the Spanish Ministry of Economy and Competitiveness, Instituto de Salud Carlos III through a 'Río Hortega' contract (CM17/00258) and reports no competing interests. Dr. Hidalgo has no conflict of interest to declare. Dr. Murru has served as a consultant, adviser, or speaker for Adamed, AstraZeneca, Bristol-Myers Squibb, Janssen-Cilag, Lundbeck, Otsuka, and Sanofi-Aventis. Dr. Pacchiarotti has received CME-related honoraria, or consulting fees from ADAMED, Janssen-Cilag and Lundbeck. Dr. Samalin has received grants, honoraria, or consulting fees from AstraZeneca, Bristol-Myers Squibb, Janssen-Cilag, Lundbeck, Otsuka, Sanofi-Aventis, and Takeda. Prof. Young has the following disclosures. Employed by King's College London. Honorary consultant SLaM (NHS UK). Paid lectures and advisory boards for all major pharmaceutical companies with drugs used in affective and related disorders. No shareholdings in pharmaceutical companies. Lead Investigator for the Embolden Study (AZ), the BCI Neuroplasticity Study, and the Aripiprazole Mania Study. Investigatorinitiated studies from AZ, Eli-Lilly, Lundbeck, and Wyeth. Grant funding (past and present): NIMH (USA), CIHR (Canada), NARSAD (USA), Stanley Medical Research Institute (USA), MRC (UK), Wellcome Trust (UK). the Royal College of Physicians (Edin), BMA (UK), UBC-VGH Foundation (Canada), WEDC (Canada), CCS Depression Research Fund (Canada), MSFHR (Canada), and NIHR (UK). Prof. Vieta has received research support from or served as consultant, adviser, or speaker for AB-Biotics, Actavis, Allergan, AstraZeneca, Bristol-Myers Squibb, Dainippon Sumitomo Pharma, Ferrer, Forest Research Institute, Gedeon Richter, Glaxo-Smith-Kline, Janssen, Lundbeck, Otsuka, Pfizer, Roche, Sanofi-Aventis, Servier, Shire, Sunovion, Takeda, Telefónica, the Brain and Behaviour Foundation, the Spanish Ministry of Science and Innovation (CIBERSAM), the Seventh European Framework Programme (ENBREC), and the Stanley Medical Research Institute. Dr. Carvalho is the recipient of a research fellowship award from the Conselho de Desenvolvimento Científico e Tecnológico (CNPq; Brazil).

\section{Role of the funder/sponsor}

The funding sources had no role in the design and conduct of the study; collection, management, analysis, and interpretation of the data; preparation, review, or approval of the manuscript; and decision to submit the manuscript for publication.

\section{References}

1. Grande I, Berk M, Birmaher B, Vieta E. Bipolar disorder. Lancet 2016;387:1561-1572.

2. Solé E, Garriga M, Valentí M, Vieta E. Mixed features in bipolar disorder. CNS Spectr 2017;22:134140.

3. Marneros A. Origin and development of concepts of bipolar mixed states. J Affect Disord 2001;67:229-240.

4. Rosenblat JD, McIntyre RS. Treatment recommendations for DSM-5-defined mixed features. CNS Spectr 2017;22:147-154.

5. Stahl SM. Mixed-up about how to diagnose and treat mixed features in major depressive episodes. CNS Spectr 2017;22:111-115.

6. American Psychiatric Association. Diagnostic and statistical manual of mental disorders (4th edn, Text Revision). Washington, DC: American Psychiatric Association, 2000.

7. American Psychiatric Association (2013) Diagnostic and statistical manual of mental disorders (5th edn). Washington DC: American Psychiatric Association, 2013.

8. Vieta E, Valentí M. Mixed states in DSM-5: implications for clinical care, education, and research. J Affect Disord 2013;148:28-36.

9. McIntyre RS, Lee Y, Mansur RB. A pragmatic approach to the diagnosis and treatment of mixed features in adults with mood disorders. CNS Spectr 2016;21(S1):25-33.

10. Kessing LV. The prevalence of mixed episodes during the course of illness in bipolar disorder. Acta Psychiatr Scand 2008;117:216-224.

11. Verdolini N, Agius M, Ferranti L, Moretti P, Piselli M, QuARTESAN R. The state of the art of the DSM-5 "with mixed features" specifier. ScientificWorldJournal 2015;2015:757258.

12. McIntyre RS, Soczynska JK, Cha DS et al. The prevalence and illness characteristics of DSM-5-defined "mixed feature specifier" in adults with major depressive disorder and bipolar disorder: results from the International Mood Disorders Collaborative Project. J Affect Disord 2015; 172:259-264.

13. Malhi GS, Byrow Y, Outhred T, Fritz K. Exclusion of overlapping symptoms in DSM-5 mixed features specifier: heuristic diagnostic and treatment implications. CNS Spectr 2017;22:126-133.

14. TаKеShima M, Ока T. DSM-5-defined "mixed features" and Benazzi's mixed depression: which is practically useful to discriminate bipolar disorder from unipolar depression in patients with depression? Psychiatry Clin Neurosci 2015;69:109-116.

15. Sнiм IH, Woo YS, Baнк W-M. Prevalence rates and clinical implications of bipolar disorder "with mixed features" as defined by DSM-5. J Affect Disord 2015; 173:120-125.

16. Tohen M, Gold AK, Sylvia LG et al. Bipolar mixed features - results from the comparative effectiveness for bipolar disorder (Bipolar CHOICE) study. J Affect Disord 2017;217:183-189. 


\section{Verdolini et al.}

17. Perugi G, Angst J, Azorin J-M et al. Mixed features in patients with a major depressive episode: the BRIDGEII-MIX study. J Clin Psychiatry 2015;76:e351-e358.

18. McElroy SL, Keck PE. Dysphoric mania, mixed states, and mania with mixed features specifier: are we mixing things up? CNS Spectr 2017;22:170-176.

19. Verdolini N, Perugi G, Samalin L et al. Aggressiveness in depression: a neglected symptom possibly associated with bipolarity and mixed features. Acta Psychiatr Scand 2017; 136:362-372.

20. Targum SD, Suppes T, Pendergrass JC et al. Major depressive disorder with subthreshold hypomania (mixed features): clinical characteristics of patients entered in a multiregional, placebo-controlled study. Prog Neuropsychopharmacol Biol Psychiatry 2016;68:9-14.

21. Malhi GS. Diagnosis of bipolar disorder: who is in a mixed state? Lancet 2013;381:1599-1600.

22. Grunze H, Vieta E, Goodwin GM et al. The World Federation of Societies of Biological Psychiatry (WFSBP) guidelines for the biological treatment of bipolar disorders: acute and long-term treatment of mixed states in bipolar disorder. World J Biol Psychiatry 2018;19:2-58.

23. Grunze H, Vieta E, Goodwin GM et al. The World Federation of Societies of Biological Psychiatry (WFSBP) guidelines for the biological treatment of bipolar disorders: update 2009 on the treatment of acute mania. World J Biol Psychiatry 2009;10:85-116.

24. Cuomo A, Nikolova VL, Yalin N, Arnone D, Fagiolini A, Young AH. Pharmacological treatment of mixed states. CNS Spectr 2017;22:186-195.

25. Rosenblat JD, McIntyre RS. Treatment of mixed features in bipolar disorder. CNS Spectr 2017;22:141-146.

26. Goodwin GM, Consensus Group of the British Association for Psychopharmacology. Evidence-based guidelines for treating bipolar disorder: revised second edition-recommendations from the British Association for Psychopharmacology. J Psychopharmacol 2009;23:346388.

27. McIntyre RS, Suppes T, Tandon R, Ostacher M. Florida best practice psychotherapeutic medication guidelines for adults with major depressive disorder. J Clin Psychiatry 2017;78:703-713

28. Woo YS, Lee JG, Jeong J-H et al. Korean medication algorithm project for bipolar disorder: third revision. Neuropsychiatr Dis Treat 2015;11:493-506.

29. Moher D, Liberati A, Tetzlaff J, Altman DG. Preferred reporting items for systematic reviews and meta-analyses: the PRISMA statement. BMJ 2009;339:b2535.

30. Graham R, Mancher M, Wolman D, Greenfield S, SteinBERG E. Clinical practice guidelines we can trust. Washington, DC: National Academies Press, 2011:266.

31. Nivoli AMA, Colom F, Murru A et al. New treatment guidelines for acute bipolar depression: a systematic review. J Affect Disord 2011;129:14-26.

32. Nivoli AMA, Murru A, Goikolea JM et al. New treatment guidelines for acute bipolar mania: a critical review. J Affect Disord 2012;140:125-141.

33. Fountoulakis KN, Vieta E, Sanchez-Moreno J, Kaprinis SG, Goikolea JM, Kaprinis GS. Treatment guidelines for bipolar disorder: a critical review. J Affect Disord 2005;86:1-10.

34. Brouwers MC, Kho ME, Browman GP et al. AGREE II: advancing guideline development, reporting and evaluation in health care. CMAJ 2010;182:E839-E842.

35. My AGREE PLUS - AGREE Enterprise website. http:// www.agreetrust.org/login/.
36. Goodwin G, Haddad P, Ferrier I et al. Evidence-based guidelines for treating bipolar disorder: revised third edition recommendations from the British Association for Psychopharmacology. J Psychopharmacol 2016;30:495553.

37. Guyatt GH, Oxman AD, Vist GE et al. GRADE: an emerging consensus on rating quality of evidence and strength of recommendations. BMJ 2008;336:924-926.

38. Shekelle PG, Woolf SH, Eccles M, Grimshaw J. Clinical guidelines: developing guidelines. BMJ 1999;318:593596.

39. Yatham LN, Kennedy SH, Parikh SV et al. Canadian Network for Mood and Anxiety Treatments (CANMAT) and International Society for Bipolar Disorders (ISBD) 2018 guidelines for the management of patients with bipolar disorder. Bipolar Disord 2018;20:97-170.

40. Fountoulakis KN, Grunze H, Vieta E et al. The International College of Neuro-Psychopharmacology (CINP) treatment guidelines for Bipolar disorder in adults (CINP-BD-2017), part 3: the clinical guidelines. Int J Neuropsychopharmacol 2017;20:180-195.

41. Malhi GS, Bassett D, Boyce P et al. Royal Australian and New Zealand College of Psychiatrists clinical practice guidelines for mood disorders. Aust N Z J Psychiatry 2015;49:1087-1206.

42. NHMRC additional levels of evidence and grades for recommendations for developers of guidelines. https://www. nhmrc.gov.au/_files_nhmrc/file/guidelines/developers/ nhmrc_levels_grades_evidence_120423.pdf.

43. Stahl SM, Morrissette DA, Faedda G et al. Guidelines for the recognition and management of mixed depression. CNS Spectr 2017;22:203-219.

44. Grunze H, Vieta E, Goodwin GM et al. The World Federation of Societies of Biological Psychiatry (WFSBP) guidelines for the biological treatment of bipolar disorders: update 2010 on the treatment of acute bipolar depression. World J Biol Psychiatry 2010;11:81-109.

45. Grunze H, Vieta E, Goodwin GM et al. The World Federation of Societies of Biological Psychiatry (WFSBP) guidelines for the biological treatment of bipolar disorders: update 2012 on the long-term treatment of bipolar disorder. World J Biol Psychiatry 2013;14:154-219.

46. Bandelow B, Zohar J, Hollander E et al. World Federation of Societies of Biological Psychiatry (WFSBP) guidelines for the pharmacological treatment of anxiety, obsessive-compulsive and post-traumatic stress disorders - first revision. World J Biol Psychiatry 2008;9:248-312.

47. Fountoulakis KN, Yatham L, Grunze $\mathrm{H}$ et al. The International College of Neuro-Psychopharmacology (CINP) treatment guidelines for bipolar disorder in adults (CINP-BD-2017), part 2: review, grading of the evidence, and a precise algorithm. Int $\mathbf{J}$ Neuropsychopharmacol 2017;20:121-179.

48. Tohen M, SAnger TM, McElroy SL et al. Olanzapine versus placebo in the treatment of acute mania. Olanzapine HGEH Study Group. Am J Psychiatry 1999;156:702-709.

49. Tohen M, Jacobs TG, Grundy SL et al. Efficacy of olanzapine in acute bipolar mania: a double-blind, placebo-controlled study. The Olanzipine HGGW Study Group. Arch Gen Psychiatry 2000;57:841-849.

50. Baker RW, Tohen M, Fawcett $\mathbf{J}$ et al. Acute dysphoric mania: treatment response to olanzapine versus placebo. J Clin Psychopharmacol 2003;23:132-137.

51. Baldessarini RJ, Hennen J, Wilson $M$ et al. Olanzapine versus placebo in acute mania: treatment responses in subgroups. J Clin Psychopharmacol 2003;23:370-376. 


\section{Mixed states and features treatment review}

52. Tohen M, McIntyre RS, Kanba S, Fujikoshi S, Katagiri H. Efficacy of olanzapine in the treatment of bipolar mania with mixed features defined by DSM-5. J Affect Disord 2014;168:136-141.

53. McIntyre RS, Cohen M, Zhao J, Alphs L, Macek TA, PANAgides J. A 3-week, randomized, placebo-controlled trial of asenapine in the treatment of acute mania in bipolar mania and mixed states. Bipolar Disord 2009;11:673686.

54. Houston JP, Tohen M, Degenhardt EK, Jamal HH, Liu LLL, Ketter TA. Olanzapine-divalproex combination versus divalproex monotherapy in the treatment of bipolar mixed episodes: a double-blind, placebo-controlled study. J Clin Psychiatry 2009;70:1540-1547.

55. Tohen M, Chengappa KNR, Suppes $\mathrm{T}$ et al. Efficacy of olanzapine in combination with valproate or lithium in the treatment of mania in patients partially nonresponsive to valproate or lithium monotherapy. Arch Gen Psychiatry 2002;59:62-69.

56. Baker RW, Brown E, Akiskal HS et al. Efficacy of olanzapine combined with valproate or lithium in the treatment of dysphoric mania. $\mathrm{Br} \mathrm{J}$ Psychiatry 2004; 185:472-478.

57. Suppes T, Eudicone J, McQuade R, Pikalov A, Carlson B. Efficacy and safety of aripiprazole in subpopulations with acute manic or mixed episodes of bipolar I disorder. J Affect Disord 2008;107:145-154.

58. Sachs G, Sanchez R, Marcus R et al. Aripiprazole in the treatment of acute manic or mixed episodes in patients with bipolar I disorder: a 3-week placebo-controlled study. J Psychopharmacol 2006;20:536-546.

59. Young AH, Oren DA, Lowy A et al. Aripiprazole monotherapy in acute mania: 12-week randomised placebo- and haloperidol-controlled study. Br J Psychiatry 2009; 194:40-48.

60. Zimbroff DL, Marcus RN, Manos G et al. Management of acute agitation in patients with bipolar disorder. J Clin Psychopharmacol 2007;27:171-176.

61. El Mallakh RS, Vieta E, Rollin L, Marcus R, Carson WH, McQuade R. A comparison of two fixed doses of aripiprazole with placebo in acutely relapsed, hospitalized patients with bipolar disorder I (manic or mixed) in subpopulations (CN138-007). Eur Neuropsychopharmacol 2010;20:776-783.

62. Kanba S, Kawasaki H, Ishigooka J, Sakamoto K, Kinoshita T, KUROKI T. A placebo-controlled, double-blind study of the efficacy and safety of aripiprazole for the treatment of acute manic or mixed episodes in Asian patients with bipolar I disorder (the AMAZE study). World J Biol Psychiatry 2014;15:113-121.

63. Vieta E, Bourin M, Sanchez R et al. Effectiveness of aripiprazole $\mathrm{v}$. haloperidol in acute bipolar mania: double-blind, randomised, comparative 12-week trial. $\mathrm{Br} \mathrm{J}$ Psychiatry 2005; 187:235-242.

64. Vieta E, T'joen C, McQuade RD et al. Efficacy of adjunctive aripiprazole to either valproate or lithium in bipolar mania patients partially nonresponsive to valproate/ lithium monotherapy: a placebo-controlled study. Am J Psychiatry 2008;165:1316-1325.

65. Vieta E, Nuamah IF, Lim P et al. A randomized, placeboand active-controlled study of paliperidone extended release for the treatment of acute manic and mixed episodes of bipolar I disorder. Bipolar Disord 2010;12:230 243.

66. Berwaerts J, Xu H, Nuamah I, Lim P, Hough D. Evaluation of the efficacy and safety of paliperidone extendedrelease in the treatment of acute mania: a randomized, double-blind, dose-response study. J Affect Disord 2012;136:e51-e60.

67. Berwaerts J, Lane R, Nuamah IF, Lim P, Remmerie B, Hough DW. Paliperidone extended-release as adjunctive therapy to lithium or valproate in the treatment of acute mania: a randomized, placebo-controlled study. J Affect Disord 2011;129:252-260.

68. Keck PE, Versiani M, Warrington L, Loebel AD, Horne RL. Long-term safety and efficacy of ziprasidone in subpopulations of patients with bipolar mania. J Clin Psychiatry 2009;70:844-851.

69. Potkin SG, Keck PE, Segal S, Ice K, English P. Ziprasidone in acute bipolar mania: a 21-day randomized, double-blind, placebo-controlled replication trial. J Clin Psychopharmacol 2005;25:301-310.

70. Stahl S, Lombardo I, Loebel A, Mandel FS. Efficacy of ziprasidone in dysphoric mania: pooled analysis of two double-blind studies. J Affect Disord 2010;122:39-45.

71. Szegedi A, Zhao J, van Willigenburg A, Nations KR, Mackle M, Panagides J. Effects of asenapine on depressive symptoms in patients with bipolar I disorder experiencing acute manic or mixed episodes: a post hoc analysis of two 3-week clinical trials. BMC Psychiatry 2011;11:101.

72. Azorin JM, SAPIN C, Weiller E. Effect of asenapine on manic and depressive symptoms in bipolar I patients with mixed episodes: results from post hoc analyses. J Affect Disord 2013;145:62-69.

73. McIntyre RS, Tohen M, Berk M, Zhao J, Weiller E. DSM-5 mixed specifier for manic episodes: evaluating the effect of depressive features on severity and treatment outcome using asenapine clinical trial data. J Affect Disord 2013;150:378-383.

74. McIntyre RS, Cohen M, Zhao J, Alphs L, Macek TA, Panagides J. Asenapine versus olanzapine in acute mania: a double-blind extension study. Bipolar Disord 2009; 11:815-826.

75. Landbloom RL, Mackle M, Wu X et al. Asenapine: efficacy and safety of 5 and $10 \mathrm{mg}$ bid in a 3-week, randomized, double-blind, placebo-controlled trial in adults with a manic or mixed episode associated with bipolar I disorder. J Affect Disord 2016;190:103-110.

76. McIntyre RS, Cohen M, Zhao J, Alphs L, Macek TA, PANAGIDES J. Asenapine in the treatment of acute mania in bipolar I disorder: a randomized, double-blind, placebocontrolled trial. J Affect Disord 2010;122:27-38.

77. Berk M, Tiller JWG, Zhao J, Yatham LN, Malhi GS, WeILler E. Effects of asenapine in bipolar I patients meeting proxy criteria for moderate-to-severe mixed major depressive episodes: a post hoc analysis. J Clin Psychiatry 2015;76:728-734.

78. Szegedi A, Calabrese JR, Stet L et al. Asenapine as adjunctive treatment for acute mania associated with bipolar disorder: results of a 12-week core study and 40week extension. J Clin Psychopharmacol 2012;32:46-55.

79. Suppes T, Ketter TA, Gwizdowski IS et al. First controlled treatment trial of bipolar II hypomania with mixed symptoms: quetiapine versus placebo. $\mathrm{J}$ Affect Disord 2013;150:37-43.

80. Zarate CA, Rothschild A, Fletcher KE, Madrid A, ZapATEL J. Clinical predictors of acute response with quetiapine in psychotic mood disorders. J Clin Psychiatry 2000;61:185-189.

81. Catapano-Friedman L. Effectiveness of quetiapine in the management of psychotic depression in an adolescent boy with bipolar disorder, mixed, with psychosis. J Child Adolesc Psychopharmacol 2001;11:205-206. 


\section{Verdolini et al.}

82. Bowden CL, Grunze H, Mullen J et al. A randomized, double-blind, placebo-controlled efficacy and safety study of quetiapine or lithium as monotherapy for mania in bipolar disorder. J Clin Psychiatry 2005;66:111-121.

83. McIntyre RS, Brecher M, Paulsson B, Huizar K, Mullen J. Quetiapine or haloperidol as monotherapy for bipolar mania-a 12-week, double-blind, randomised, parallelgroup, placebo-controlled trial. Eur Neuropsychopharmacol 2005; 15:573-585.

84. Cutler AJ, Datto C, Nordenhem A, Minkwitz M, Acevedo L, DARKo D. Extended-release quetiapine as monotherapy for the treatment of adults with acute mania: a randomized, double-blind, 3-week trial. Clin Ther 2011;33:16431658.

85. Garriga M, Solé E, González-Pinto A et al. Efficacy of quetiapine XR vs. placebo as concomitant treatment to mood stabilizers in the control of subthreshold symptoms of bipolar disorder: results from a pilot, randomized controlled trial. Eur Neuropsychopharmacol 2017;27:959969.

86. Sachs GS, Greenberg WM, Starace A et al. Cariprazine in the treatment of acute mania in bipolar I disorder: a double-blind, placebo-controlled, phase III trial. J Affect Disord 2015;174:296-302.

87. Durgam S, Starace A, Li D et al. The efficacy and tolerability of cariprazine in acute mania associated with bipolar I disorder: a phase II trial. Bipolar Disord 2015;17:63-75.

88. Calabrese JR, Keck PE Jr, Starace A et al. Efficacy and safety of low- and high-dose cariprazine in acute and mixed mania associated with bipolar I disorder. J Clin Psychiatry 2015;00:284-292. Available from: http://www. psychiatrist.com/jcp/article/pages/2015/v76n03/ v76n0306.aspx

89. Vieta E, Durgam S, Lu K, Ruth A, Debelle M, Zukin S. Effect of cariprazine across the symptoms of mania in bipolar I disorder: analyses of pooled data from phase II/ III trials. Eur Neuropsychopharmacol 2015;25:18821891

90. Vieta E, Durgam S, Lu K, Laszlovszky i, Patel MeW. Efficacy of cariprazine in subgroups of bipolar patients with manic episodes, mixed episodes, and with or without psychotic symptoms. Eur Neuropsychopharmacol 2017;27:S936-S937.

91. Khanna S, Vieta E, Lyons B, Grossman F, Eerdekens M, KRAMER M. Risperidone in the treatment of acute mania: double-blind, placebo-controlled study. Br J Psychiatry 2005; 187:229-234.

92. Hirschfeld RMA, Keck PE, Kramer M et al. Rapid antimanic effect of risperidone monotherapy: a 3-week multicenter, double-blind, placebo-controlled trial. Am J Psychiatry 2004;161:1057-1065.

93. Smulevich AB, Khanna S, Eerdekens M, Karcher K, KraMER M, Grossman F. Acute and continuation risperidone monotherapy in bipolar mania: a 3-week placebo-controlled trial followed by a 9-week double-blind trial of risperidone and haloperidol. Eur Neuropsychopharmacol 2005; 15:75-84.

94. Perlis RH, Baker RW, Zarate CA et al. Olanzapine versus risperidone in the treatment of manic or mixed States in bipolar I disorder: a randomized, double-blind trial. J Clin Psychiatry 2006;67:1747-1753.

95. Sachs GS, Grossman F, Ghaemi SN, Окамоto A, Bowden CL. Combination of a mood stabilizer with risperidone or haloperidol for treatment of acute mania: a double- blind, placebo-controlled comparison of efficacy and safety. Am J Psychiatry 2002;159:1146-1154.

96. Suppes T, McElroy SL, Gilbert J, Dessain EC, Cole JO Clozapine in the treatment of dysphoric mania. Biol Psychiatry 1992;32:270-280.

97. Masi G, Mucci M, Millepiedi S. Clozapine in adolescent inpatients with acute mania. J Child Adolesc Psychopharmacol 2002;12:93-99.

98. Tohen M, Goldberg JF, Gonzalez-Pinto Arrillaga AM et al. A 12-week, double-blind comparison of olanzapine vs haloperidol in the treatment of acute mania. Arch Gen Psychiatry 2003;60:1218-1226.

99. Weisler RH, Kalali AH, Ketter TA, SPD417 Study Group. A multicenter, randomized, double-blind, placebocontrolled trial of extended-release carbamazepine capsules as monotherapy for bipolar disorder patients with manic or mixed episodes. J Clin Psychiatry 2004;65:478-484.

100. Weisler RH, Keck PE, Swann AC et al. Extended-release carbamazepine capsules as monotherapy for acute mania in bipolar disorder: a multicenter, randomized, doubleblind, placebo-controlled trial. J Clin Psychiatry 2005;66:323-330.

101. Weisler RH, Hirschfeld R, Cutler AJ et al. Extendedrelease carbamazepine capsules as monotherapy in bipolar disorder : pooled results from two randomised, double-blind, placebo-controlled trials. CNS Drugs 2006;20:219-231.

102. Freeman TW, Clothier JL, Pazzaglia P, Lesem MD, Swann AC. A double-blind comparison of valproate and lithium in the treatment of acute mania. Am $\mathrm{J}$ Psychiatry 1992; 149:108-111.

103. Bowden CL, Swann AC, Calabrese JR et al. A randomized, placebo-controlled, multicenter study of divalproex sodium extended release in the treatment of acute mania. J Clin Psychiatry 2006;67:1501-1510.

104. Bowden CL, Brugger AM, Swann AC et al. Efficacy of divalproex vs lithium and placebo in the treatment of mania. The Depakote Mania Study Group. JAMA 1994;271:918-924.

105. Swann AC, Bowden CL, Morris D et al. Depression during mania. Treatment response to lithium or divalproex. Arch Gen Psychiatry 1997;54:37-42.

106. Grunze H, Erfurth A, Amann B, Giupponi G, Kammerer C, WALDEN J. Intravenous valproate loading in acutely manic and depressed bipolar I patients. J Clin Psychopharmacol 1999;19:303-309.

107. Kushner SF, Khan A, Lane R, Olson WH. Topiramate monotherapy in the management of acute mania: results of four double-blind placebo-controlled trials. Bipolar Disord 2006;8:15-27.

108. Marcotte D. Use of topiramate, a new anti-epileptic as a mood stabilizer. J Affect Disord 1998;50:245-251.

109. Chengappa KN, Rathore D, Levine $\mathbf{J}$ et al. Topiramate as add-on treatment for patients with bipolar mania. Bipolar Disord 1999;1:42-53.

110. Vieta E, Torrent C, Garcia-Ribas $\mathrm{G}$ et al. Use of topiramate in treatment-resistant bipolar spectrum disorders. J Clin Psychopharmacol 2002;22:431-435.

111. Barzman DH, DelBello MP, Kowatch RA et al. Adjunctive topiramate in hospitalized children and adolescents with bipolar disorders. J Child Adolesc Psychopharmacol 2005;15:931-937.

112. Benedetti A, Lattanzi L, Pini S, Musetti L, Dell'Osso L, Cassano GB. Oxcarbazepine as add-on treatment in patients with bipolar manic, mixed or depressive episode. J Affect Disord 2004;79:273-277. 


\section{Mixed states and features treatment review}

113. Mokhber N, Lane CJ, Azarpazhoom MR et al. Anticonvulsant treatments of dysphoric mania: a trial of gabapentin, lamotrigine and carbamazepine in Iran. Neuropsychiatr Dis Treat 2008:4:227-234.

114. McElroy SL, Soutullo CA, Keck PE, Kmetz GF. A pilot trial of adjunctive gabapentin in the treatment of bipolar disorder. Ann Clin Psychiatry 1997;9:99-103.

115. Perugi G, Toni C, Ruffolo G, Sartini S, Simonini E, AkisKAL H. Clinical experience using adjunctive gabapentin in treatment-resistant bipolar mixed states. Pharmacopsychiatry 1999;32:136-141.

116. Altshuler LL, Keck PE, McElroy SL et al. Gabapentin in the acute treatment of refractory bipolar disorder. Bipolar Disord 1999;1:61-65.

117. Sokolski KN, Green C, Maris DE, DeMet EM. Gabapentin as an adjunct to standard mood stabilizers in outpatients with mixed bipolar symptomatology. Ann Clin Psychiatry 1999;11:217-222.

118. Vieta E, Martinez-Arán A, Nieto E et al. Adjunctive gabapentin treatment of bipolar disorder. Eur Psychiatry 2000;15:433-437.

119. Valentí M, Benabarre A, García-Amador M, Molina O, Bernardo M, Vieta E. Electroconvulsive therapy in the treatment of mixed states in bipolar disorder. Eur Psychiatry 2008;23:53-56.

120. Gruber NP, Dilsaver SC, Shoaib AM, Swann AC. ECT in mixed affective states: a case series. J ECT 2000;16:183188.

121. Medda P, Toni C, Mariani MG, De Simone L, Mauri M, Perugi G. Electroconvulsive therapy in 197 patients with a severe, drug-resistant bipolar mixed state. J Clin Psychiatry 2015;76:1168-1173.

122. StrömGRen LS. Electroconvulsive therapy in Aarhus, Denmark, in 1984: its application in nondepressive disorders. Convuls Ther 1988;4:306-313.

123. Devanand DP, Polanco P, Cruz R et al. The efficacy of ECT in mixed affective states. J ECT 2000;16: $32-37$.

124. Ciapparelli A, Dell'Osso L, Tundo A et al. Electroconvulsive therapy in medication-nonresponsive patients with mixed mania and bipolar depression. J Clin Psychiatry 2001;62:552-555.

125. Medda P, Perugi G, Zanello S, Ciuffa M, Rizzato S, CasSANo GB. Comparative response to electroconvulsive therapy in medication-resistant bipolar I patients with depression and mixed state. J ECT 2010;26:82-86.

126. Patkar A, Gilmer W, PAe $C$ et al. A 6 week randomized double-blind placebo-controlled trial of ziprasidone for the acute depressive mixed state. PLoS One 2012;7:e34757.

127. Benazzi F, Berk M, Frye MA, Wang W, Barraco A, ToHEN M. Olanzapine/fluoxetine combination for the treatment of mixed depression in bipolar I disorder. J Clin Psychiatry 2009;70:1424-1431.

128. Tohen M, Vieta E, Calabrese $\mathbf{J}$ et al. Efficacy of olanzapine and olanzapine-fluoxetine combination in the treatment of bipolar I depression. Arch Gen Psychiatry 2003;60:1079-1088.

129. Tohen M, McDonnell DP, Case M et al. Randomised, double-blind, placebo-controlled study of olanzapine in patients with bipolar I depression. $\mathrm{Br} \mathrm{J}$ Psychiatry 2012;201:376-382.

130. Loebel A, Cucchiaro J, Silva $R$ et al. Lurasidone monotherapy in the treatment of bipolar I depression: a randomized, double-blind, placebo-controlled study. Am J Psychiatry 2014;171:160-168.

131. Loebel A, Cucchiaro J, Silva R et al. Lurasidone as adjunctive therapy with lithium or valproate for the treatment of bipolar I depression: a randomized, doubleblind, placebo-controlled study. Am J Psychiatry 2014;171:169-177.

132. Suppes T, Kroger H, Pikalov A, Loebel A. Lurasidone adjunctive with lithium or valproate for bipolar depression: a placebo-controlled trial utilizing prospective and retrospective enrolment cohorts. J Psychiatr Res 2016;78:86-93.

133. McIntyre R, Cucchiaro J, Pikalov A, Kroger H, Loebel A. Lurasidone in the treatment of bipolar depression with mixed (subsyndromal hypomanic) features: post hoc analysis of a randomized placebo-controlled trial. J Clin Psychiatry 2015;76:398-405.

134. Suppes T, Silva R, Cucchiaro J et al. Lurasidone for the treatment of major depressive disorder with mixed features: a randomized, double-blind, placebo-controlled study. Am J Psychiatry 2016;173:400-407.

135. Swann AC, Fava M, Tsai J, Mao Y, Pikalov A, Loebel A. Lurasidone for major depressive disorder with mixed features and irritability: a post-hoc analysis. CNS Spectr 2017;22:228-235.

136. Tsai J, Thase ME, Mao Y, NG-Mak D, Pikalov A, Loebel A. Lurasidone for major depressive disorder with mixed features and anxiety: a post-hoc analysis of a randomized, placebo-controlled study. CNS Spectr 2017;22:236245.

137. Sramek J, Loebel A, Murphy M, Mao Y, Pikalov A, Cutler NR. Lurasidone in post-menopausal females with major depressive disorder with mixed features: post-hoc analysis of a placebo-controlled trial. Prog Neuropsychopharmacol Biol Psychiatry 2017:78:12-17.

138. Dilsaver SC, Swann SC, Chen Y-W et al. Treatment of bipolar depression with carbamazepine: results of an open study. Biol Psychiatry 1996;40:935-937.

139. Perugi G, Medda P, Reis J, Rizzato S, Giorgi Mariani M, MAURI M. Clinical subtypes of severe bipolar mixed states. J Affect Disord 2013;151:1076-1082.

140. Joas E, Karanti A, Song J, Goodwin GM, Lichtenstein P, LANDÉn M. Pharmacological treatment and risk of psychiatric hospital admission in bipolar disorder. Br J Psychiatry 2017;210:197-202.

141. Tohen M, Mintz J, Bowden CL. Analysis of bipolar maintenance treatment with lithium versus olanzapine utilizing Multi-state Outcome Analysis of Treatments (MOAT). Bipolar Disord 2016;18:282-287.

142. Tohen M, Greil W, Calabrese JR et al. Olanzapine versus lithium in the maintenance treatment of bipolar disorder: a 12-month, randomized, double-blind, controlled clinical trial. Am J Psychiatry 2005;162:1281-1290.

143. Cipriani A, Reid K, Young AH, Macritchie K, Geddes J. Valproic acid, valproate and divalproex in the maintenance treatment of bipolar disorder. Cochrane Database Syst Rev 2013;(10):CD003196.

144. Calabrese JR, Shelton MD, Rapport DJ et al. A 20-month, double-blind, maintenance trial of lithium versus divalproex in rapid-cycling bipolar disorder. Am J Psychiatry 2005;162:2152-2161.

145. Backlund L, Ehnvall A, Hetta J, Isacsson G, Ågren H. Identifying predictors for good lithium response - a retrospective analysis of 100 patients with bipolar disorder using a life-charting method. Eur Psychiatry 2009;24:171-177.

146. Kessing LV, Hellmund G, Geddes JR, Goodwin GM, ANDERSEN PK. Valproate $v$. lithium in the treatment of bipolar disorder in clinical practice: observational nationwide register-based cohort study. $\mathrm{Br} \mathbf{J}$ Psychiatry 2011;199:57-63. 


\section{Verdolini et al.}

147. Weisler RH, Nolen WA, Neijber A, Hellovist $\AA$, Paulsson B. Continuation of quetiapine versus switching to placebo or lithium for maintenance treatment of bipolar I disorder. J Clin Psychiatry 2011;72:1452-1464.

148. Nolen WA, Weisler RH. The association of the effect of lithium in the maintenance treatment of bipolar disorder with lithium plasma levels: a post hoc analysis of a double-blind study comparing switching to lithium or placebo in patients who responded to quetiapine (Trial 144). Bipolar Disord 2013;15:100-109.

149. Keller MB, Lavori PW, Coryell W, Endicott J, Mueller TI. Bipolar I: a five-year prospective follow-up. J Nerv Ment Dis 1993;181:238-245.

150. Prien RF, Himmelhoch JM, Kupfer DJ. Treatment of mixed mania. J Affect Disord 1988;15:9-15.

151. Bowden CL, Coluins MA, McElroy SL et al. Relationship of mania symptomatology to maintenance treatment response with divalproex, lithium, or placebo. Neuropsychopharmacology 2005;30:1932-1939.

152. Bowden CL, Calabrese JR, McElroy SL et al. A randomized, placebo-controlled 12-month trial of divalproex and lithium in treatment of outpatients with bipolar I disorder. Divalproex Maintenance Study Group. Arch Gen Psychiatry 2000;57:481-489.

153. Ketter TA, Kalali AH, Weisler RH, SPD417 Study Group. A 6-month, multicenter, open-label evaluation of beaded, extended-release carbamazepine capsule monotherapy in bipolar disorder patients with manic or mixed episodes. J Clin Psychiatry 2004;65:668-673.

154. Tohen M, Calabrese JR, Sachs GS et al. Randomized, placebo-controlled trial of olanzapine as maintenance therapy in patients with bipolar I disorder responding to acute treatment with olanzapine. Am J Psychiatry 2006; 163:247-256.

155. Tohen M, Sutton VK, Calabrese JR, Sachs GS, Bowden CL. Maintenance of response following stabilization of mixed index episodes with olanzapine monotherapy in a randomized, double-blind, placebo-controlled study of bipolar 1 disorder. J Affect Disord 2009;116:43-50.

156. Tohen M, Chengappa KNR, Suppes $\mathrm{T}$ et al. Relapse prevention in bipolar I disorder: 18-month comparison of olanzapine plus mood stabiliser v. mood stabiliser alone. Br J Psychiatry 2004;184:337-345.

157. Vieta E, Suppes T, Eggens I, Persson I, Paulsson B, BreCHER M. Efficacy and safety of quetiapine in combination with lithium or divalproex for maintenance of patients with bipolar I disorder (international trial 126). J Affect Disord 2008;109:251-263.

158. Suppes T, Vieta E, Liu S, Brecher M, Paulsson B, Trial 127 Investigators. Maintenance treatment for patients with bipolar I disorder: results from a North American study of quetiapine in combination with lithium or divalproex (trial 127). Am J Psychiatry 2009;166:476-488.

159. Vieta E, Suppes T, Ekholm B, Udd M, Gustafsson U. Long-term efficacy of quetiapine in combination with lithium or divalproex on mixed symptoms in bipolar I disorder. J Affect Disord 2012;142:36-44.

160. Bowden CL, Vieta E, Ice KS, Schwartz JH, Wang PP, VersaVel M. Ziprasidone plus a mood stabilizer in subjects with bipolar I disorder: a 6-month, randomized, placebo-controlled, double-blind trial. J Clin Psychiatry 2010;71:130-137.

161. Yatham LN, Fountoulakis KN, Rahman Z et al. Efficacy of aripiprazole versus placebo as adjuncts to lithium or valproate in relapse prevention of manic or mixed episodes in bipolar I patients stratified by index manic or mixed episode. J Affect Disord 2013;147:365-372.
162. Marcus R, Khan A, Rollin L et al. Efficacy of aripiprazole adjunctive to lithium or valproate in the long-term treatment of patients with bipolar I disorder with an inadequate response to lithium or valproate monotherapy: a multicenter, double-blind, randomized study. Bipolar Disord 2011;13:133-144.

163. Woo YS, BAHK W-M, Chung MY et al. Aripiprazole plus divalproex for recently manic or mixed patients with bipolar I disorder: a 6-month, randomized, placebo-controlled, double-blind maintenance trial. Hum Psychopharmacol 2011;26:543-553.

164. Carlson BX, Ketter TA, Sun W et al. Aripiprazole in combination with lamotrigine for the long-term treatment of patients with bipolar I disorder (manic or mixed): a randomized, multicenter, double-blind study (CN138-392). Bipolar Disord 2012;14:41-53.

165. Benabarre A, Vieta E, Colom F, Martínez A, Reinares M, Corbella B. Treatment of mixed mania with risperidone and mood stabilizers. Can J Psychiatry 2001; 46:866-867.

166. Woo YS, BAHK W-M, Jon D-I et al. Risperidone in the treatment of mixed state bipolar patients: results from a 24-week, multicenter, open-label study in Korea. Psychiatry Clin Neurosci 2010;64:28-37.

167. Vanelle JM, Loo H, Galinowski A et al. Maintenance ECT in intractable manic-depressive disorders. Convuls Ther 1994;10:195-205.

168. Medda P, Mauri M, Fratta $\mathrm{S}$ et al. Long-term naturalistic follow-up of patients with bipolar depression and mixed state treated with electroconvulsive therapy. J ECT 2013;29:179-188.

169. Mosolov SNMS. Primenenie elektrosudorozhnoi terapii dlia obryva kontinual'- nogo techeniia terapevticheski rezistentnykh affektivnogo $\mathrm{i}$ shizoaffektivnogo psikhozov. Zh Nevropatol Psikhiatr Im S S Korsakova 1990;90:121-125.

170. Ketter TA, Sarma K, Silva R, Kroger H, Cucchiaro J, Loebel A. Lurasidone in the long-term treatment of patients with bipolar disorder: a 24-week open-label extension study. Depress Anxiety 2016;33:424-434.

171. Pikalov A, Tsai J, Mao Y, Silva R, Cucchiaro J, Loebel A. Long-term use of lurasidone in patients with bipolar disorder: safety and effectiveness over 2 years of treatment. Int J Bipolar Disord 2017;5:9.

172. Calabrese JR, Pikalov A, Streicher C, Cucchiaro J, Mao Y, Loebel A. Lurasidone in combination with lithium or valproate for the maintenance treatment of bipolar I disorder. Eur Neuropsychopharmacol 2017;27:865-876.

173. Goldberg JF, NG-Mak D, Siu C, Chuang C-C, Rajagopalan $\mathrm{K}$, Loebel A. Remission and recovery associated with lurasidone in the treatment of major depressive disorder with subthreshold hypomanic symptoms (mixed features): post-hoc analysis of a randomized, placebo-controlled study with longer-term extension. CNS Spectr 2017;22:220-227.

174. Pacchiarotti I, Bond DJ, Baldessarini RJ et al. The International Society for Bipolar Disorders (ISBD) task force report on antidepressant use in bipolar disorders. Am J Psychiatry 2013;170:1249-1262.

175. Solmi M, Murru A, Pacchiarotti I et al. Safety, tolerability, and risks associated with first- and second-generation antipsychotics: a state-of-the-art clinical review. Ther Clin Risk Manag 2017;13:757-777.

176. Popovic D, Reinares M, Goikolea JM, Bonnin CM, GonzaLez-Pinto A, Vieta E. Polarity index of pharmacological agents used for maintenance treatment of bipolar disorder. Eur Neuropsychopharmacol 2012;22:339-346. 


\section{Mixed states and features treatment review}

177. Vieta E, Berk M, Schulze TG et al. Bipolar disorders. Nat Rev Dis Primers 2018;4:18008.

178. Murru A. Electroconvulsive therapy in bipolar mixed states: an overlooked option. J Clin Psychiatry 2015;76: e1149-e1150.

179. Rosa AR, Cruz N, Franco $\mathrm{C}$ et al. Why do clinicians maintain antidepressants in some patients with acute mania? J Clin Psychiatry 2010;71:1000-1006.

180. Montoya A, Pérez Sánchez Toledo J, Gilaberte I et al. Patterns of drug treatment for manic episode in the clinical practice. Outcomes of the Spanish sample in the EMBLEM Study. Actas Esp Psiquiatr 2007;35:315322.

181. Kessing LV, Vradi E, Andersen PK. Nationwide and population-based prescription patterns in bipolar disorder. Bipolar Disord 2016;18:174-182.

182. Barbuti M, Pacchiarotti I, Vieta E et al. Antidepressantinduced hypomania/mania in patients with major depression: evidence from the BRIDGE-II-MIX study. J Affect Disord 2017;219:187-192.

183. Valentí M, Pacchiarotti I, Rosa AR et al. Bipolar mixed episodes and antidepressants: a cohort study of bipolar I disorder patients. Bipolar Disord 2011;13:145-154.

184. Pacchiarotti I, Mazzarini L, Kotzalidis GD et al. Mania and depression. Mixed, not stirred. J Affect Disord 2011;133:105-113.

185. Baldessarini RJ, Undurraga J, Vázquez GH et al. Predominant recurrence polarity among 928 adult international bipolar I disorder patients. Acta Psychiatr Scand 2012;125:293-302.

186. Vieta E, Nolen WA, Grunze H, Licht RW, Goodwin G. A European perspective on the Canadian guidelines for bipolar disorder. Bipolar Disord 2005;7(Suppl 3):73-76.

187. Mazzarini L, Kotzalidis GD, Piacentino D et al. Is recurrence in major depressive disorder related to bipolarity and mixed features? Results from the BRIDGE-II-Mix study. J Affect Disord 2018;229:164-170.

188. Popovic D, Vieta E, Azorin J-M et al. Suicide attempts in major depressive episode: evidence from the BRIDGEII-Mix study. Bipolar Disord 2015;17:795-803.

189. Petri E, Bacci O, Barbuti M et al. Obesity in patients with major depression is related to bipolarity and mixed features: evidence from the BRIDGE-II-Mix study. Bipolar Disord 2017; 19:458-464.

190. Perugi G, Angst J, Azorin J-M et al. Relationships between mixed features and borderline personality disorder in 2811 patients with major depressive episode. Acta Psychiatr Scand 2016;133:133-143.

191. Ratheesh A, Davey C, Hetrick S et al. A systematic review and meta-analysis of prospective transition from major depression to bipolar disorder. Acta Psychiatr Scand 2017; 135:273-284.

192. Kessing LV, Willer I, Andersen PK, Bukh JD. Rate and predictors of conversion from unipolar to bipolar disorder: a systematic review and meta-analysis. Bipolar Disord 2017;19:324-335.
193. Morrissette DA. Do no harm: a paradigm shift in the unchecked use of antidepressants. CNS Spectr 2017;22:118-119.

194. Stahl SM, Morrissette DA. Does a "whiff" of mania in a major depressive episode shift treatment from a classical antidepressant to an atypical/second-generation antipsychotic? Bipolar Disord 2017;19:595-596.

195. Angst J, Cui L, Swendsen J et al. Major depressive disorder with subthreshold bipolarity in the National Comorbidity Survey Replication. Am J Psychiatry 2010;167:1194-1201.

196. Malhi GS, Kuiper S. Chronobiology of mood disorders Acta Psychiatr Scand 2013;128:2-15.

197. Malhi GS, Porter RJ. Are "buy-polar" forces and "trypolar" thinking expanding bipolarity? Aust N Z J Psychiatry 2014;48:697-700.

198. Akiskal HS, Hantouche EG, Bourgeois ML et al. Gender, temperament, and the clinical picture in dysphoric mixed mania: findings from a French national study (EPIMAN). J Affect Disord 1998;50:175-186.

199. Perugi G, Akiskal HS, Micheli $C$ et al. Clinical subtypes of bipolar mixed states: validating a broader European definition in 143 cases. J Affect Disord 1997;43:169-180.

200. Benazzi F. Age at onset of bipolar II depressive mixed state. Psychiatry Res 2001;103:229-235.

201. Koukopoulos A, SANI G. DSM-5 criteria for depression with mixed features: a farewell to mixed depression. Acta Psychiatr Scand 2014;129:4-16.

202. Kessing LV, Bauer M, Nolen WA, Severus E, Goodwin GM, Geddes J. Effectiveness of maintenance therapy of lithium vs other mood stabilizers in monotherapy and in combinations: a systematic review of evidence from observational studies. Bipolar Disord 2018.1-13. Available from: https://doi.org/doi.wiley.com/10.1111/bdi. 12623

203. Swann AC. Mixed features: evolution of the concept, past and current definitions, and future prospects. CNS Spectr 2017;22:161-169.

204. Colom F, Vieta E, Martinez-Aran A et al. A randomized trial on the efficacy of group psychoeducation in the prophylaxis of recurrences in bipolar patients whose disease is in remission. Arch Gen Psychiatry 2003;60:402-407.

\section{Supporting Information}

Additional Supporting Information may be found in the online version of this article:

Appendix S1. Detailed search strategy.

Figure S1. PRISMA flow-chart.

Table S1. Grading of the categories of evidence.

Table S2. Operational definition of recommendation grades.

Table S3. List of excluded studies, with reasons.

Table S4. Comparison of the included guidelines: evidence of efficacy, not recommended treatments.

Table S5. Methodological quality assessment by the two independent reviewers. 